\title{
Ionic Mechanisms Underlying Inflammatory Mediator-Induced Sensitization of Dural Afferents
}

\author{
Andrea H. Vaughn ${ }^{1,2,3}$ and Michael S. Gold ${ }^{3,4}$ \\ ${ }^{1}$ Department of Neural and Pain Sciences, Dental School, and ${ }^{2}$ Baltimore Medical Scientist Training Program, University of Maryland, Baltimore, Maryland \\ 21201, and ${ }^{3}$ Department of Anesthesiology and ${ }^{4}$ Pittsburgh Center for Pain Research, University of Pittsburgh, Pittsburgh, Pennsylvania 15213
}

\begin{abstract}
Migraineurs experience debilitating headaches that result from neurogenic inflammation of the dura and subsequent sensitization of dural afferents. Given the importance of inflammatory mediator (IM)-induced dural afferent sensitization to this pain syndrome, the present study was designed to identify ionic mechanisms underlying this process. Trigeminal ganglion neurons from adult female Sprague Dawley rats were acutely dissociated 10-14 d after application of retrograde tracer DiI onto the dura. Modulation of ion channels and changes in excitability were measured in the absence and presence of IMs (in $\mu \mathrm{M}$ : 1 prostaglandin, 10 bradykinin, and 1 histamine) using whole-cell and perforated-patch recordings. Fura- 2 was used to assess changes in intracellular $\mathrm{Ca}^{2+}$. IMs modulated a number of currents in dural afferents, including those both expected and/or previously described [i.e., an increase in tetrodotoxin-resistant voltagegated $\mathrm{Na}^{+}$current (TTX-R $I_{\mathrm{Na}}$ ) and a decrease in voltage-gated $\mathrm{Ca}^{2+}$ current] as well currents never before described in sensory neurons (i.e., a decrease in a $\mathrm{Ca}^{2+}$-dependent $\mathrm{K}^{+}$current and an increase in a $\mathrm{Cl}^{-}$current), and produced a sustained elevation in intracellular $\mathrm{Ca}^{2+}$. Although several of these currents, in particular TTX-R $I_{\mathrm{Na}}$, appear to contribute to the sensitization of dural afferents, the $\mathrm{Cl}^{-}$ current is the primary mechanism underlying this process. Activation of this current plays a dominant role in the sensitization of dural afferents because of the combination of the density and biophysical properties of TTX-R $I_{\mathrm{Na}}$, and the high level of intracellular $\mathrm{Cl}^{-}$in these neurons. These results suggest novel targets for the development of antimigraine agents.
\end{abstract}

\section{Introduction}

Migraine is a neurological disorder characterized by incapacitating head pain. Compelling evidence indicates that neurogenic inflammation of the dura and subsequent dural afferent sensitization are fundamentally important for initiating migraine pain (Ray and Wolff, 1940; Strassman et al., 1996; Sarchielli et al., 2000; Burstein, 2001). However, the ionic mechanisms involved in dural afferent sensitization have yet to be discovered.

A feature that distinguishes nociceptive afferents from all other primary sensory neurons is that they can be sensitized by mediators released at sites of inflammation. Identification of the underlying mechanisms of sensitization remains an active area of investigation because of the critical role this increase in afferent excitability plays in ongoing pain and hypersensitivity (hyperalgesia) observed in the presence of tissue injury. Given the direct link between ion channel activity and neuronal excitability, ion channels have remained a primary focus of this line of investigation. Recent evidence suggests that the specific ion channels underlying the sensitization of nociceptive afferents varies as a function of target of innervation. For example, there are differ-

Received Dec. 7, 2009; revised Feb. 27, 2010; accepted April 20, 2010.

This work was supported by National Institutes of Health Grants NS059153 (A.H.V.), NS41384 (M.S.G.), and DE018252 (M.S.G.). We thank Drs. Daniel Weinreich and Brian Davis for helpful comments during the preparation of this manuscript.

Correspondence should be addressed to Dr. Michael S. Gold, Department of Anesthesiology, University of Pittsburgh, 3500 Terrace Street, Room E1440 BST, Pittsburgh, PA 15213. E-mail: msg22@pitt.edu.

DOI:10.1523/JNEUROSCI.6053-09.2010

Copyright $\odot 2010$ the authors $\quad 0270-6474 / 10 / 307878-11 \$ 15.00 / 0$ ences between the mechanisms underlying the acute sensitization of afferents innervating the colon and those innervating glabrous skin (Gold and Traub, 2004). Similar differences have been described for afferents innervating the muscle (Harriott et al., 2006), ileum (Stewart et al., 2003), bladder (Yoshimura and de Groat, 1999), and colon (Beyak et al., 2004) in response to persistent inflammation. Although the differences described to date suggest the involvement of distinct neurobiological processes, increases in voltage-gated $\mathrm{Na}^{+}$and/or decreases in voltage-gated or $\mathrm{Ca}^{2+}$-dependent $\mathrm{K}^{+}$currents appear to be mechanisms common to sensitization of nociceptive afferents in these previous studies. In marked contrast to the results from these previous studies, we recently described inflammatory mediator (IM)induced changes in dural afferents that appeared to reflect processes in addition to those previously described (Harriott and Gold, 2009). Given that IM-induced sensitization of this population of afferents appears to play an essential role in the headache associated with migraine (Ray and Wolff, 1940; Strassman et al., 1996; Sarchielli et al., 2000; Burstein, 2001), the purpose of the present study was to identify the mechanisms underlying the IMinduced sensitization of these afferents.

Acutely dissociated retrogradely labeled dural afferents from adult female rats were studied with whole-cell patch-clamp and $\mathrm{Ca}^{2+}$-imaging techniques. Results from this analysis suggest that, in addition to changes in $\mathrm{Na}^{+}$currents common to the sensitization of other afferent populations, and the inhibition of a $\mathrm{K}^{+}$ current that appears to be unique to dural afferents, the primary mechanism of IM-induced sensitization of dural afferents appears to be the activation of $\mathrm{Cl}^{-}$current. 


\section{Materials and Methods}

Animals

Adult female Sprague Dawley rats (Harlan) weighing between 180 and $290 \mathrm{~g}$ were used for all experiments. Rats were housed two per cage at the University of Pittsburgh animal facility on a $12 \mathrm{~h}$ light/dark schedule with food and water available ad libitum. Before all procedures, animals were deeply anesthetized with an intraperitoneal injection $(1 \mathrm{ml} / \mathrm{kg})$ of mixture containing ketamine $(55 \mathrm{mg} / \mathrm{kg})$, xylazine $(5.5 \mathrm{mg} / \mathrm{kg})$, and acepromazine $(1.1 \mathrm{mg} / \mathrm{kg})$. Experiments were approved by the University of Pittsburgh Institutional Animal Care and Use Committee and performed in accordance with National Institutes of Health Guide for the Care and Use of Laboratory Animals. All efforts were used to minimize the total number of animals used.

Afferents innervating the dura were identified as previously described after application of DiI to the dura (Harriott and Gold, 2008). Ten to $14 \mathrm{~d}$ after DiI application, trigeminal ganglia were removed, enzymatically treated, and mechanically dissociated as previously described (Harriott et al., 2006). Changes in currents, intracellular $\mathrm{Ca}^{2+}$, and excitability were measured 2-8 h after cells were plated.

\section{Electrophysiology}

All whole-cell and perforated-patch-clamp recordings were performed with a HEKA EPC10 amplifier (HEKA). Data were low-pass filtered at $5-10 \mathrm{kHz}$ with a four-pole Bessel filter and digitally sampled at $25-100 \mathrm{kHz}$. Ionic solutions were chosen to study specific currents in isolation. For all solutions, $\mathrm{pH}$ was adjusted to between 7.2 and 7.4 with Tris base (unless otherwise stated) and the osmolality adjusted to between 310 and $325 \mathrm{mOsm}$ with sucrose. Thick-walled borosilicate glass ( $1.5 \mathrm{~mm}$ internal diameter; WPI) electrodes were pulled (Sutter P2000) such that, when filled with electrode solution, the resistance was $<5 \mathrm{M} \Omega$.

Voltage clamp. A standard protocol was used to facilitate comparisons between neurons. After establishing whole-cell access, membrane resistance and capacitance were determined with hyperpolarizing voltage steps from $-60 \mathrm{mV}$. Baseline data were collected over 2-10 min to ensure the particular current under study was stable as well as to facilitate detection of IM-induced changes. IMs were then applied and changes in currents were monitored. Voltage-clamp protocols were used to assess the impact of IMs on current activation, inactivation and deactivation as well as $\mathrm{Ca}^{2+}$ dependence with the specific details of each protocol described in conjunction with the description of the specific currents. To facilitate assessment of the reversal potential for IM-induced currents, a voltage ramp from +50 to $-100 \mathrm{mV}$ over $100 \mathrm{~ms}$ was used. Finally, gramicidin perforated-patch recording was used to assess the resting concentration of intracellular $\mathrm{Cl}^{-}$in dural afferents. Bath and electrode solutions were constructed to either reflect physiological solutions or to facilitate the study of specific currents in isolation. The details of each solution used are as follows.

To isolate $\mathrm{Na}^{+}$currents, the electrode solution was composed of the following (in $\mathrm{mm}$ ): $100 \mathrm{Cs}$-methanesulfonate, 40 tetraethylammonium (TEA)-Cl, $5 \mathrm{NaCl}, 1 \mathrm{CaCl}_{2}, 2 \mathrm{MgCl}_{2}, 10$ HEPES, 11 EGTA, 2 Mg-ATP, and $1 \mathrm{Li}$-GTP. Bath solution contained the following (in $\mathrm{mM}$ ): $35 \mathrm{Na}-$ methanesulfonate, 65 choline-Cl, 30 TEA-Cl, $2.5 \mathrm{CaCl}_{2}, 5 \mathrm{MgCl}_{2}, 0.05$ $\mathrm{CdCl}_{2}, 10$ HEPES, and 10 glucose.

To isolate $\mathrm{K}^{+}$currents, the electrode solution was composed of the following (in $\mathrm{mM}$ ): $110 \mathrm{~K}$-methanesulfonate, $30 \mathrm{KCl}, 5 \mathrm{NaCl}, 1 \mathrm{CaCl}_{2}, 2$ $\mathrm{MgCl}_{2}, 10$ HEPES, 11 EGTA, $2 \mathrm{Mg}$-ATP, and $1 \mathrm{Li}-\mathrm{GTP}$. Bath solution contained the following (in $\mathrm{mM}$ ): $3 \mathrm{KCl}, 130$ choline- $\mathrm{Cl}, 2.5 \mathrm{CaCl}_{2}, 0.6$ $\mathrm{MgCl}_{2}, 0.1$ niflumic acid (NFA), 10 HEPES, 10 glucose.

To isolate $\mathrm{Ca}^{2+}$ currents, the electrode solution was composed of the following (in $\mathrm{mM}$ ): $100 \mathrm{Cs}$-methanesulfonate, $5 \mathrm{Na}$-methanesulfonate, 40 TEA-Cl, $1 \mathrm{CaCl}_{2}, 2 \mathrm{MgCl}_{2}, 11$ EGTA, 10 HEPES. Bath solution contained the following (in $\mathrm{mM}$ ): 100 choline-Cl, 30 TEA-Cl, $2.5 \mathrm{CaCl}_{2}, 0.6$ $\mathrm{MgCl}_{2}, 0.1$ NFA, 10 HEPES, 10 glucose.

Initial characterization of IM-evoked currents were performed with an electrode solution composed of the following (in mM): $110 \mathrm{~K}$-methanesulfonate, $30 \mathrm{KCl}, 5 \mathrm{NaCl}, 1 \mathrm{CaCl}_{2}, 2 \mathrm{MgCl}_{2}, 10 \mathrm{HEPES}, 11$ EGTA, 2 Mg-ATP, 1 Li-GTP; and bath solution containing the following (in mM): $3 \mathrm{KCl}, 130 \mathrm{NaCl}, 2.5 \mathrm{CaCl}_{2}, 0.6 \mathrm{MgCl}_{2}, 10$ HEPES, 10 glucose.
The contribution of monovalent and divalent cations to the IMinduced current was assessed by manipulating concentrations of $\mathrm{K}^{+}$and $\mathrm{Na}^{+}$and $\mathrm{Ca}^{2+}$. The contribution of monovalent cations to the IMinduced current was minimized with an electrode solution containing the following (in mM): 100 Cs-methanesulfonate, $30 \mathrm{CsCl}, 1 \mathrm{CaCl}_{2}, 2$ $\mathrm{MgCl}_{2}, 10$ HEPES, 11 EGTA, $2 \mathrm{Mg}$-ATP, 1 Li-GTP; and bath solution containing the following (in $\mathrm{mm}$ ): 130 choline- $\mathrm{Cl}, 2.5 \mathrm{CaCl}_{2}, 0.6 \mathrm{MgCl}_{2}$, 10 HEPES, 10 glucose.

To further analyze the source of $\mathrm{Ca}^{2+}$ responsible for the IM-induced activation of $\mathrm{Cl}^{-}$currents, four different manipulations were formed as follows: (1) the addition of $\mathrm{Cd}^{2+}(50 \mu \mathrm{M})$ to the bath solution to block influx via voltage-dependent $\mathrm{Ca}^{2+}$ channels, (2) the addition of ruthenium red to the bath solution to block influx via ligand-gated ion channels, (3) the substitution of BAPTA $(10 \mathrm{~mm})$ for EGTA $(11 \mathrm{~mm})$ in the electrode solution, and (4) the use of the combination of an electrode solution with $\mathrm{Ca}^{2+}$ artificially buffered to $\sim 620 \mathrm{nM}$ with an electrode solution containing EGTA (1.2 mM), $\mathrm{Ca}^{2+}(1 \mathrm{mM})$, and $\mathrm{Mg}^{2+}(2 \mathrm{~mm})$, in which influx via voltage-gated $\mathrm{Ca}^{2+}$ channels (VGCCs) was also blocked by the addition of $\mathrm{Cd}^{2+}(50 \mu \mathrm{M})$ to the bath solution. MaxChelator was used to generate estimates of resting free intracellular $\mathrm{Ca}^{2+}$.

The reversal potential of IM-induced currents was determined using gramicidin perforated-patch recordings and a bath solution containing the following (in mM): 100 choline-Cl, $30 \mathrm{TEA}-\mathrm{Cl}, 2.5 \mathrm{CaCl}_{2}, 0.6 \mathrm{MgCl}_{2}$, 10 HEPES, 10 glucose.

Current clamp. Excitability was assessed in the presence and absence of test compounds as previously described (Harriott and Gold, 2009). A neuron was considered sensitized if application of a test solution resulted in a hyperpolarization of action potential (AP) threshold, decrease in rheobase, and/or an increase in the response to suprathreshold stimulation $>2$ SDs from the baseline mean. Current injection was used in the present study as a means to bypass natural processes underlying the transduction of what would be primarily mechanical (changes in vessel diameter) and chemical stimuli in the dura. Given evidence that IMs can sensitize transduction processes (i.e., TRPV1) as well as the ion channels underlying action potential initiation and propagation, changes in excitability described in the present study would serve to amplify IM-induced modulation of transduction processes that should also occur at afferent terminals in vivo.

\section{$\mathrm{Ca}^{2+}$ imaging}

Neurons were incubated with $2.5 \mu \mathrm{M} \mathrm{Ca}{ }^{2+}$ indicator fura-2 AM ester with $0.025 \%$ pluronic as described previously (Lu et al., 2006), and IMinduced $\mathrm{Ca}^{2+}$ transients were acquired on a PC running Metafluor software (Molecular Devices) via a CCD camera (Roper Scientific; model RTE/CCD $1300)$. The ratio $(R)$ of fluorescence emission $(510 \mathrm{~nm})$ in response to $340 /$ $380 \mathrm{~nm}$ excitation [controlled by a lambda 10-2 filter changer (Sutter Instrument)] was acquired at $1 \mathrm{~Hz}$ during IM applications.

\section{Drugs}

All salts and test compounds were obtained from Sigma-Aldrich. IMs consisted of bradykinin $(10 \mu \mathrm{M})$, histamine $(1 \mu \mathrm{M})$, and prostaglandin $\mathrm{E}_{2}$ $(1 \mu \mathrm{M})$, where bradykinin was dissolved in $1 \%$ acetic acid $(23.58 \mathrm{~mm}$ stock concentration), prostaglandin $\mathrm{E}_{2}\left(\mathrm{PGE}_{2}\right)$ was dissolved in $100 \%$ ETOH (10 mM stock concentration), and histamine was dissolved in water (100 mM stock concentration). All stock solutions were stored at $-20^{\circ} \mathrm{C}$ until the day of use. IM-vehicle bath containing the final concentration of ETOH $(0.01 \%)$ and acetic acid $(0.001 \%)$ was used as a control. NFA was dissolved in $100 \%$ ETOH. Ruthenium red was dissolved in water.

There were four primary reasons for the use of an "inflammatory soup" in the present study rather than single mediators. First, we (Gold and Traub, 2004; Harriott and Gold, 2009) and, more importantly, others (Strassman et al., 1996; Oshinsky, 2006; Jakubowski et al., 2007; Levy et al., 2008; Edelmayer et al., 2009) have used a mixture to sensitize dural afferents, with the studies performed by others on the afferent terminals. Second, although an important and interesting question, the focus of the study was not on which mediators and/or mediator receptors underlie the sensitization of dural afferents, but which ion channels are downstream from these mediators. Third, data from microdialysis studies of 
A

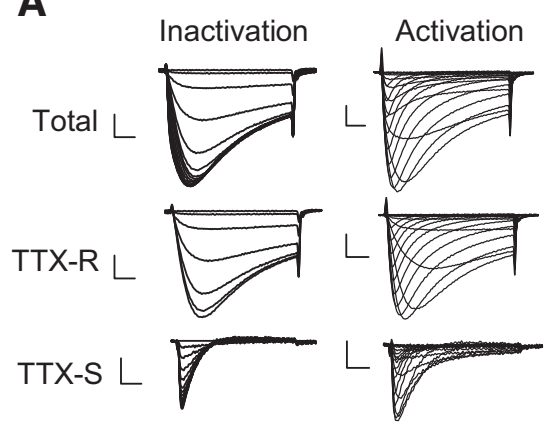

B

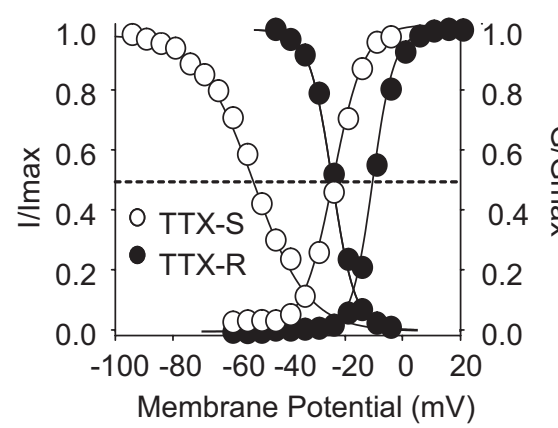

C

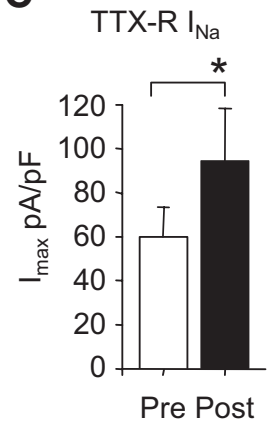

D

TTX-S I $\mathrm{Ia}_{\mathrm{Na}}$

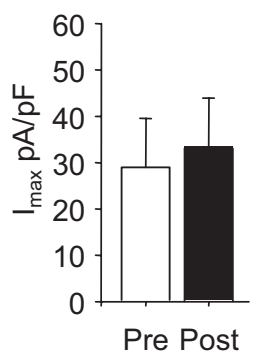

Figure 1. Inflammatory mediators increase TTX-R Na ${ }^{+}$currents in dural afferents. $\mathrm{Na}^{+}$currents were recorded in dural afferents $(n=13)$ before and after IM application. $A$, Two types of $\mathrm{Na}{ }^{+}$ currents were detected in dural afferents. A high-threshold slowly activating and slowly inactivating TTX-R Na ${ }^{+}$current and a low-threshold rapidly activating and inactivating TTX-S Na ${ }^{+}$current. $B$, Example of the voltage dependence of inactivation and activation when data were fitted with a Boltzmann equation. $\boldsymbol{C}$, After IM application (Post), there was a significant increase in maximal $\mathrm{TTX}_{-\mathrm{R} \mathrm{Na}}{ }^{+}$current density in dural afferents relative to the baseline current density (Pre). Calibration: $2 \mathrm{nA}, 2 \mathrm{~ms},{ }^{*} p<0.05 . \boldsymbol{D}$, However, there was no significant difference in TTX-S Na ${ }^{+}$current density $(p>0.05)$. Error bars indicate SE.

injured tissue (Hargreaves et al., 1994; Roszkowski et al., 1997; Lepinski et al., 2000) as well as the CSF from migraine patients during a migraine (Sarchielli et al., 2000) indicate that multiple mediators are released at the same time. Furthermore, evidence suggests that a combination of mediators such as mast cell (Levy et al., 2007) and cyclooxygenase (Jakubowski et al., 2005) products contribute to the sensitization of dural afferents and/or migraine. Fourth, there is already evidence that the IM-induced modulation of at least one ion channel (i.e., $\mathrm{Na}_{\mathrm{V}} 1.9$ ) requires a combination of mediators (Maingret et al., 2008). Therefore, we chose to pool mediators rather than attempt to identify the mediator or specific combination of mediators that underlies the sensitization of dural afferents.

\section{Data analysis}

Data were analyzed with PulseFit (HEKA), SigmaPlot, and SigmaStat software (Systat Software). Conductance-voltage $(G-V)$ curves were constructed from $I-V$ curves by dividing the evoked current by the driving force on the current, such that $G=I /\left(V_{\mathrm{m}}-V_{\text {rev }}\right)$, where $V_{\mathrm{m}}$ is the potential at which current was evoked and $V_{\text {rev }}$ is the reversal potential for the current that was measured directly (for $\mathrm{K}^{+}$and $\mathrm{Na}^{+}$currents). Instantaneous $I-V$ data, obtained from the tail currents measured after activation of voltage-gated $\mathrm{Ca}^{2+}$ currents, was used to construct $G-V$ curves for voltage-gated $\mathrm{Ca}^{2+}$ currents. Activation and steady-state availability data were fitted with a Boltzmann equation of the following form: $G=G_{\max } / 1+\exp \left[\left(V_{0.5}-V_{\mathrm{m}}\right) / k\right]$, where $G$ is observed conductance, $G_{\max }$ is the calculated maximal conductance, $V_{0.5}$ is the potential for half-activation or inactivation, $V_{\mathrm{m}}$ is command potential, and $k$ is the slope factor. $\mathrm{K}^{+}$currents were corrected for series resistance voltage error. For $\mathrm{Ca}^{2+}$ imaging, the IM-induced change in the fluorescence ratio was determined by subtracting the baseline ratio from the peak value. The decay of the IM-induced $\mathrm{Ca}^{2+}$ transient was analyzed as time to $50 \%$ decay of the peak $\left(T_{50}\right)$.

For comparisons of parametric data collected before and after IM application, either a paired $t$ test or repeated-measures ANOVA were used. Otherwise, a Wilcoxon or Friedman test was used for nonparametric analysis. For unpaired comparisons of the percentage reduction in rheobase, a $t$ test was used for parametric data and a Mann-Whitney $U$ for nonparametric analysis. Data were considered statistically significant when $p<0.05$. All data are represented as mean $\pm \mathrm{SE}$.

\section{Results}

Data were collected from 186 dural afferents acutely dissociated from 36 female Sprague Dawley rats. Of these, 131 were studied in voltage clamp and 45 were studied in current clamp and 25 were studied with fura-2-based microfluorimetry. The size distribution of these neurons was similar to that of our previous study (Harriott and Gold, 2009) with a median cell body capacitance of $29.54 \mathrm{pF}$ (with 21.3 and 37.0 as 25 th and 75 th percentiles).
Inflammatory mediators increase voltage-gated $\mathrm{Na}^{+}$currents We recently described significant increases in the AP overshoot and rate of rise in dural afferents after application of IMs (bradykinin, $10 \mu \mathrm{M}$; histamine, $1 \mu \mathrm{M}$; and prostaglandin $\mathrm{E}_{2}, 1 \mu \mathrm{M}$ ) (Harriott and Gold, 2009). Since VGSCs (voltage-gated $\mathrm{Na}^{+}$channels) are primarily responsible for the upstroke of the action potential, we predicted that these IM-induced changes in the AP waveform reflected an increase in $\mathrm{Na}^{+}$currents $\left(I_{\mathrm{Na}}\right)$. For steady-state availability, $I_{\mathrm{Na}}$ was elicited with a $15 \mathrm{~ms}$ test pulse to $-10 \mathrm{mV}$ after a series of $500 \mathrm{~ms}$ prepulses from -120 to $-5 \mathrm{mV}$. To isolate tetrodotoxin-resistant currents (TTX-R $I_{\mathrm{Na}}$ ) from TTX-sensitive currents (TTX-S $I_{\mathrm{Na}}$ ), a $500 \mathrm{~ms}$ prepulse to a potential between -40 and $-30 \mathrm{mV}$ was used to inactivate TTX-S $I_{\mathrm{Na}}$. The prepulse potential used for each neuron was based on results from the steady-state availability data for total $\mathrm{Na}^{+}$current evoked in each neuron. To validate this approach for separation of TTX-S from TTX-R $I_{\mathrm{Na}}$, TTX (100 nM) was used in five dural afferents and the currents isolated with both methods were identical (data not shown). TTX-S currents were isolated by digitally subtracting TTX-R currents from the total $I_{\mathrm{Na}}$. To examine changes in the voltage dependence of activation, $I_{\mathrm{Na}}$ was elicited with test pulses from -60 to $+65 \mathrm{mV}$ after a $100 \mathrm{~ms}$ prepulse to $-110 \mathrm{mV}$. TTX-R $I_{\mathrm{Na}}$ was again isolated with a prepulse to a potential between -40 and $-30 \mathrm{mV}$, and TTX-S currents were isolated by digital subtraction (Fig. $1 A, B$ ).

As described in other afferent populations, two general types of $I_{\mathrm{Na}}$ were detected in dural afferents. These included a relatively low threshold, rapidly activating, rapidly inactivating TTX-S $I_{\mathrm{Na}}$ (Fig. $1 A$ ) and a relatively high threshold, more slowly activating and inactivating TTX-R $I_{\mathrm{Na}}$ (Fig. $1 A$ ). No persistent current was detected, although the voltage protocols used were not optimized to detect the presence of a low threshold persistent current. In dural afferents, peak TTX-S $I_{\mathrm{Na}}$ density was $28.6 \pm 10.6 \mathrm{pA} / \mathrm{pF}$, whereas that of TTX-R $I_{\mathrm{Na}}$ was $65.3 \pm 19.3 \mathrm{pA} / \mathrm{pF}$ at a test potential of $-10 \mathrm{mV}(n=13)$. TTX-S and TTX-R $I_{\mathrm{Na}}$ were detectable in every dural afferent studied. Parameters describing the voltage dependence of activation and inactivation of TTX-S and -R $I_{\mathrm{Na}}$ are summarized in Table 1.

Consistent with our prediction, TTX-R $I_{\mathrm{Na}}$ was significantly (i.e., $>2$ SDs from baseline) increased in 12 of 13 dural afferents after IM application (Fig. 1C). There was no significant increase in TTX-S $I_{\mathrm{Na}}$ after IM application (Fig. $1 D$ ). There were small but significant IM-induced changes in the biophysical properties of 
Table 1. IM-induced changes in the biophysical properties of TTX-R and TTX-S Na ${ }^{+}$currents

\begin{tabular}{|c|c|c|c|c|c|c|c|c|}
\hline & \multicolumn{4}{|l|}{ Inactivation } & \multicolumn{4}{|l|}{ Activation } \\
\hline & \multicolumn{2}{|l|}{$V_{1 / 2}$} & \multicolumn{2}{|l|}{ Slope } & \multicolumn{2}{|l|}{$V_{1 / 2}$} & \multicolumn{2}{|l|}{ Slope } \\
\hline & Pre-IM & Post-IM & Pre-IM & Post-IM & Pre-IM & Post-IM & Pre-IM & Post-IM \\
\hline TTX-R & $-26.83 \pm 1.4$ & $-27.59 \pm 1.9$ & $4.54 \pm 0.2$ & $4.34 \pm 0.2$ & $-8.46 \pm 0.8$ & $-10.61 \pm 1.0^{*}$ & $4.28 \pm 0.4$ & $4.08 \pm 0.3$ \\
\hline TTX-S & $-66.59 \pm 7.8$ & $-68.3 \pm 3.4$ & $9.05 \pm 1.0$ & $8.49 \pm 2.4$ & $-19.46 \pm 3.1$ & $-21.92 \pm 3.0^{*}$ & $7.18 \pm 1.1$ & $6.48 \pm 1.2$ \\
\hline
\end{tabular}

There were small but significant differences in the voltage dependence of activation of TTX-R and TTX-S Na ${ }^{+}$currents after IM application. Both currents displayed a small hyperpolarizing shift in the $V_{1 / 2}$ of activation after IM.

*Significant difference between pre-IM and post-IM, where $p<0.05$.

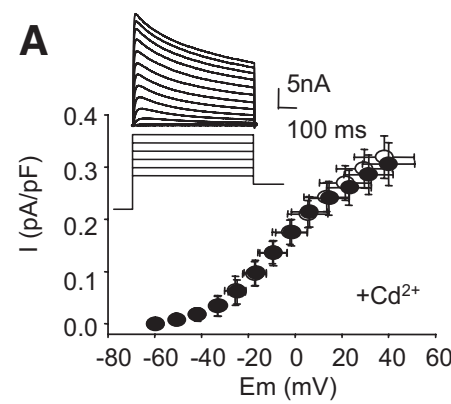

B $\quad$ C
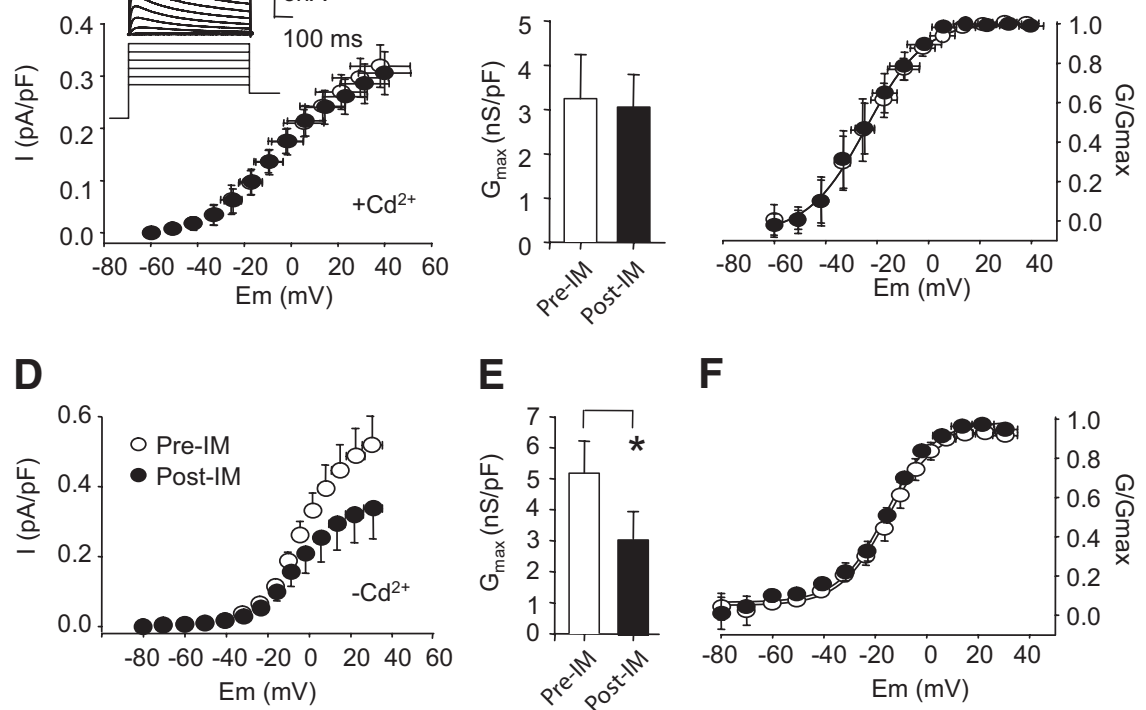

E

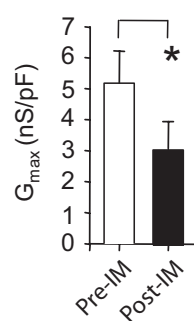

$\mathbf{F}$

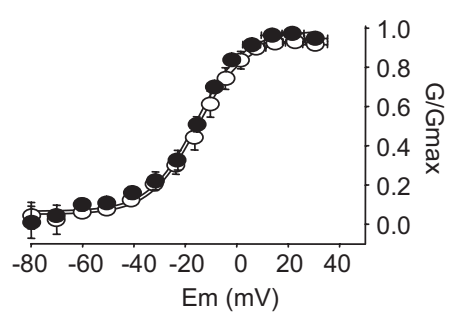

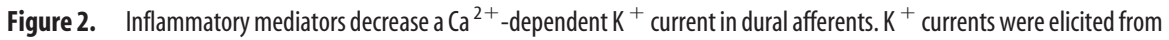
dural afferents $(n=14)$ before and after IM application. In the presence of $50 \mu \mathrm{M} \mathrm{Cd}^{2+}$, to block voltage-gated $\mathrm{Ca}^{2+}$ currents, IMs did not reduce $\mathrm{K}^{+}$current density at any potential $(\boldsymbol{A})$. Furthermore, IMs did not significantly decrease the maximal conductance in the presence of $\mathrm{Cd}^{2+}(\boldsymbol{B})$ and produced no shift in the voltage dependence of activation (C). $\boldsymbol{D}$, In the absence of $\mathrm{Cd}^{2+}$, IMs reduced $\mathrm{K}^{+}$current density at positive potentials. IMs also significantly decreased the maximal conductance $(\boldsymbol{E})$. However, there was no shift in the voltage dependence of activation of $\mathrm{K}^{+}$currents $(\boldsymbol{F}) . I-V$ and $G-V$ data were corrected for voltage errors associated with uncompensated series resistance. $\boldsymbol{A}$, Inset, Example of $\mathrm{K}^{+}$currents elicited in dural afferents with the voltage protocol shown beneath current traces. ${ }^{*} p<0.05$. Error bars indicate $S E$.

TTX-R and TTX-S $I_{\mathrm{Na}}$, which included a hyperpolarizing shift in the voltage dependence of activation (Table 1).

\section{Inflammatory mediators decrease $\mathrm{Ca}^{2+}$-dependent $\mathrm{K}^{+}$current}

There is a growing body of evidence from a number of investigators that persistent inflammation results in a significant decrease in voltage-dependent $\mathrm{K}^{+}$currents (Yoshimura and de Groat, 1999; Stewart et al., 2003; Harriott et al., 2006) and, more relevantly, that inflammatory mediators including $\mathrm{PGE}_{2}$ (Nicol et al., 1997) and NGF (Zhang et al., 2002) produce a rapid decrease in $\mathrm{K}^{+}$current. Therefore, we examined the possibility that decreases in $\mathrm{K}^{+}$currents $\left(I_{\mathrm{K}}\right)$ also contribute to IM-induced dural afferent sensitization. $\mathrm{K}^{+}$currents were elicited with $10 \mathrm{mV}, 500$ ms voltage steps between -60 and $+60 \mathrm{mV}$ after a $500 \mathrm{~ms}$ prepulse to $-120 \mathrm{mV}$. The reversal potential for $\mathrm{K}^{+}$was determined by eliciting tail currents with voltage steps from -110 to $-50 \mathrm{mV}$ in $10 \mathrm{mV}$ increments, after a test pulse to $+40 \mathrm{mV}$. Furthermore, since both voltage- and $\mathrm{Ca}^{2+}$-dependent $\mathrm{K}^{+}$currents contribute to primary afferent excitability, currents were recorded in the absence and presence of the voltage-dependent $\mathrm{Ca}^{2+}$ channel blocker $\mathrm{Cd}^{2+}(50 \mu \mathrm{M})$. IMs had no detectable influence on voltage-dependent $\mathrm{K}^{+}$currents evoked in the presence of $\mathrm{Cd}^{2+}(n=$ $7)$, as assessed by the voltage dependence of channel activation (Fig. $2 B$ ) and the maximal conductance (Fig. $2 B$ ). In contrast, when $\mathrm{Cd}^{2+}$ was omitted from the bath solution $(n=7)$, an IM-induced suppression of $\mathrm{K}^{+}$current was detected. The result was a significant decrease in maximal conductance for total outward current (Fig. 2C). To begin to identify the channel sensitive to the actions of IMs, the experiment was repeated in the presence of iberiotoxin (IbTx) $(100 \mathrm{nM} ; n=3)$ to selectively block large-conductance $\mathrm{Ca}^{2+}$-dependent $\mathrm{K}^{+}$currents (BK). Preapplication of IbTx failed to occlude the actions of IMs, suggesting BK channels do not underlie the IM-sensitive current. Together, results from this series of experiments suggest that IMs suppress a $\mathrm{Ca}^{2+}$ dependent $\mathrm{K}^{+}$current in dural afferents different from that previously described in other sensory neurons.

\section{Inflammatory mediators activate $\mathrm{Cl}^{-}$ currents in dural afferents}

Although an increase in $I_{\mathrm{Na}}$ and decrease in $I_{\mathrm{K}}$ could account for the IM-induced sensitization of dural afferents, given minimal shifts in the voltage dependence of activation of either current and the fact that these channels are not active close to the resting membrane potential, they are unlikely to account for the IM-induced changes in passive electrophysiological properties, in particular, membrane depolarization and decreased input resistance reported recently (Harriott and Gold, 2009). Therefore, to identify the ion channel(s) involved in IM-induced changes in passive electrophysiological properties of dural afferents, IM-activated currents were recorded at a holding potential of $-60 \mathrm{mV}$. Consistent with the observed IM-induced membrane depolarization, a significant increase in inward current (mean, $10.7 \pm 2.9 \mathrm{pA} / \mathrm{pF}$ ) (Fig. $3 A, C$ ) was observed after application of IMs to dural afferents $(n=7)$. To begin to identify the basis for this IM-induced current, current was evoked from a series of holding potentials ranging between -60 and $+10 \mathrm{mV}$. Data from this series of experiments $(n=7)$ indicated that the IM-induced current had a reversal potential of approximately $-30 \mathrm{mV}$ (Fig. $3 \mathrm{~B}$ ), which was close to the calculated equilibrium potential for $\mathrm{Cl}^{-}$under our recording conditions $(-34 \mathrm{mV})$. Therefore, we tested the prediction that the IM-induced current was mediated by anion flux. IM-induced currents were measured again after reducing extracellular $\mathrm{Cl}^{-}$concentration from 140 to 
$36 \mathrm{~mm}$, which produced an equimolar concentration of $\mathrm{Cl}^{-}$inside and outside the cell. Consistent with our prediction, the decrease in extracellular $\mathrm{Cl}^{-}$concentration $(n=6)$ resulted in an IM-induced current with a reversal potential at $0 \mathrm{mV}$ (Fig. 3B) and, consequently, an increase in current density evoked at $-60 \mathrm{mV}$ (Fig. $3 C)$. Moreover, bath application of nonselective $\mathrm{Cl}^{-}$channel blocker NFA (10 $\mu \mathrm{M})$ reversed the IM-induced increase in holding current (Fig. $3 C)(n=5)$. Given the nature of this IM-induced current, we subsequently refer to it as $I_{\mathrm{IM}-\mathrm{Cl}}$.

\section{Activation of $I_{\mathrm{IM}-\mathrm{Cl}}$ is dependent on an increase in the concentration of intracellular $\mathrm{Ca}^{2+}\left(\left[\mathrm{Ca}^{2+}\right]_{\text {in }}\right)$}

Although a $\mathrm{Ca}^{2+}$-dependent $\mathrm{Cl}^{-}$current

has yet to be described in trigeminal ganglion neurons, evidence from nodose ganglion neurons suggests that bradykinin is capable of activating a Cl${ }^{-}$current that is $\mathrm{Ca}^{2+}$ dependent $(\mathrm{Oh}$ and Weinreich, 2004). Therefore, to assess the contribution of $\mathrm{Ca}^{2+}$ to $I_{\mathrm{IM}-\mathrm{Cl}}$, currents were recorded using intracellular BAPTA (10 $\mathrm{mM})$ to replace EGTA $(11 \mathrm{~mm})$. Consistent with the suggestion that an increase in $\left[\mathrm{Ca}^{2+}\right]_{\text {in }}$ is important for activation of the $I_{\mathrm{IM}-\mathrm{Cl}}$, the increase in $\mathrm{Cl}^{-}$current was significantly attenuated by 10 mM BAPTA (Fig. $4 A)(n=7)$.

To determine whether influx through VGCCs provides the source of $\mathrm{Ca}^{2+}$ that activates the $I_{\mathrm{IM}-\mathrm{Cl}}$, currents were measured under conditions in which $\mathrm{Na}^{+}$and $\mathrm{K}^{+}$currents were minimized by replacing intracellular $\mathrm{K}^{+}$with $\mathrm{Cs}^{+}$and extracellular $\mathrm{Na}^{+}$with choline, leaving $\mathrm{Cl}^{-}$and $\mathrm{Ca}^{2+}$ unchanged. Currents were elicited with $100 \mathrm{~ms}$ test pulses from -70 to $+50 \mathrm{mV}$ after a $40 \mathrm{~ms}$ prepulse to $0 \mathrm{mV}$ to evoke $\mathrm{Ca}^{2+}$ influx (Fig. 4 B). Driving an increase in intracellular $\mathrm{Ca}^{2+}$ with this protocol alone was insufficient to activate $\mathrm{Cll}^{-}$current in dural afferents. However, the current-voltage relationship for $I_{\mathrm{IM}-\mathrm{Cl}}$ [resolved by digital subtraction (Fig. 4C) $(n=8)$ of currents evoked before and after application of IMs] was clearly altered by this protocol, exhibiting pronounced inward rectification that appeared to reflect an increase in outward current between -30 and $0 \mathrm{mV}$. Furthermore, $I_{\text {IM-Cl }}$ decreased at voltage steps $>0 \mathrm{mV}$ (Fig. $4 C$ ). These data were consistent with the possibility that $\mathrm{Ca}^{2+}$ influx via voltagegated $\mathrm{Ca}^{2+}$ currents facilitates $I_{\mathrm{IM}-\mathrm{Cl}}$, particularly at potentials between -30 and $0 \mathrm{mV}$.

To confirm that the shape of the $I-V$ curve in Figure $4 C$ reflected the influence of $\mathrm{Ca}^{2+}$ influx through VGCCs, $I_{\mathrm{IM}-\mathrm{Cl}}$ was examined again under recording conditions in which intracellular $\mathrm{Ca}^{2+}$ was artificially elevated to $\sim 620 \mathrm{nM}$ (with the reduction of EGTA to $1.2 \mathrm{mM}$ ) and $\mathrm{Ca}^{2+}$ influx via VGCCs was blocked by the addition $50 \mu \mathrm{M} \mathrm{Cd}^{2+}$ to the bath solution. Despite the elevated intracellular $\mathrm{Ca}^{2+}$ concentration in dural afferents studied under these recording conditions $(n=6)$, the NFA-sensitive current at $-60 \mathrm{mV}$ was comparable with that observed under our standard whole-cell recording conditions when intracellular $\mathrm{Ca}^{2+}$ was buffered to $\sim 45 \mathrm{~nm}$ (i.e., $<1 \mathrm{pA} / \mathrm{pF}$ ). Furthermore, the IM-induced inward current was comparable with that observed when $\mathrm{Ca}^{2+}$ influx was facilitated with a prepulse to $0 \mathrm{mV}$ (Fig. $4 C$ ) and in the absence of a prepulse to facilitate $\mathrm{Ca}^{2+}$ influx (Fig. $3 C$ ). However, under conditions in which $\mathrm{Ca}^{2+}$ influx was blocked by $\mathrm{Cd}^{2+}$, the $I-V$ relationship for $I_{\mathrm{IM}-\mathrm{Cl}}$ was linear (i.e., no increase in outward current between -30 and $0 \mathrm{mV}$, and no
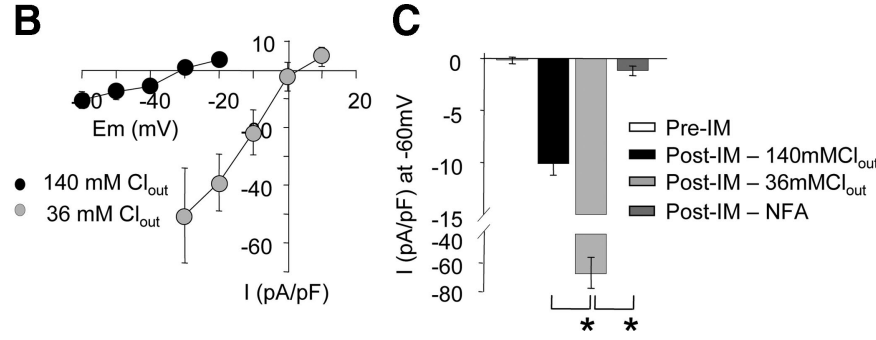

decrease in outward current at potentials $>0 \mathrm{mV})$. These observations further suggest that $\mathrm{Ca}^{2+}$ influx via VGCCs may facilitate $I_{\mathrm{IM}-\mathrm{Cl}}$ efflux but is neither necessary nor sufficient for the activation of $I_{\text {IM-Cl}}$.

To further substantiate this suggestion and rule out the possibility that $\mathrm{Ca}^{2+}$ influx via VGCCs contributes to the activation of $\mathrm{Cl}^{-}$current secondary to an IM-induced shift in the voltage dependence of activation of VGCCs, we recorded $\mathrm{Ca}^{2+}$ currents directly $(n=5)$, before and after application of IMs. Highthreshold voltage-gated $\mathrm{Ca}^{2+}$ currents were the only currents detected in dural afferents. Although these currents did exhibit rundown, it was monitored until currents were stabilized $(\sim 10$ min) before the application of IMs. No evidence of a lowthreshold current was detected after application of IMs (Fig. 5B). In contrast, however, application of IMs produced a significant $(p<0.05)$ decrease in peak $\mathrm{Ca}^{2+}$ current (Fig. 5A,B). The voltage dependence of $\mathrm{Ca}^{2+}$ current activation was examined with the instantaneous current-voltage relationship derived from tail currents. IM application did not shift the voltage dependence of activation of $\mathrm{Ca}^{2+}$ currents (Fig. 5C), suggesting a voltageindependent mode of current suppression as has been described by others (Dolphin and Scott, 1987).

There is evidence that bradykinin (Vellani et al., 2001) and $\mathrm{PGE}_{2}$ (Pitchford and Levine, 1991; Schnizler et al., 2008) can sensitize TRPV1, providing a source of $\mathrm{Ca}^{2+}$ for the activation of $I_{\text {IM-Cl}}$. And although an IM-induced activation of such a current should have impacted reversal potential measurements of $I_{\mathrm{IM}-\mathrm{Cl}}$, we sought to rule out $\mathrm{Ca}^{2+}$ influx via a TRP channel as a source of $\mathrm{Ca}^{2+}$ contributing to the activation of $I_{\mathrm{IM}-\mathrm{Cl}}$ at resting membrane potential. Toward that end, neurons were studied in the presence of the nonselective $\mathrm{Ca}^{2+}$ channel blocker ruthenium red $(10 \mu \mathrm{M}$; $n=9$ ). Although we confirmed the ability of ruthenium red to block capsaicin-evoked currents $(n=4)$ (data not shown), ruthenium red failed to block the IM-induced membrane depolarization, increase in holding current and decrease in input resistance (e.g., IM-induced decrease in input resistance was $74 \pm$ 13 and $52 \pm 22 \%$ of baseline in the absence and presence of ruthenium red, respectively; $p>0.05)$. These results suggested an IM-induced release of $\mathrm{Ca}^{2+}$ from intracellular stores as a source of $\mathrm{Ca}^{2+}$ for the activation of $I_{\mathrm{IM}-\mathrm{Cl}}$.

To assess this possibility, we examined the impact of IMs on $\left[\mathrm{Ca}^{2+}\right]_{\text {in }}$ in dural afferents measured directly with fura-2. Application of IMs to dural afferents resulted in a dramatic increase in $\left[\mathrm{Ca}^{2+}\right]_{\text {in }}$ in 9 of 10 neurons tested (Fig. 6), whereas an IM- 
A

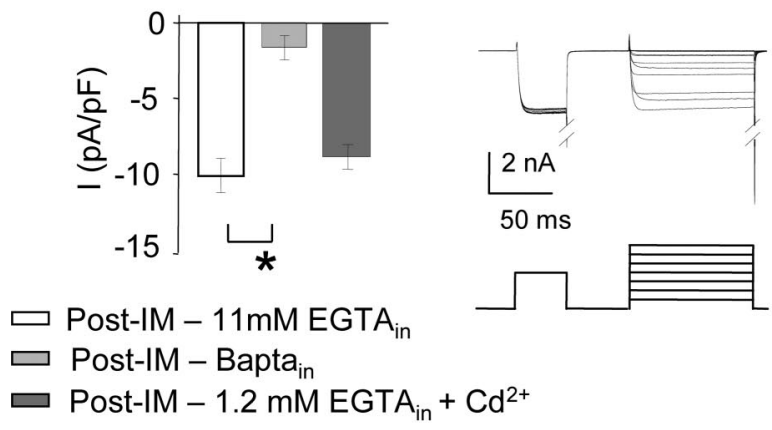

C

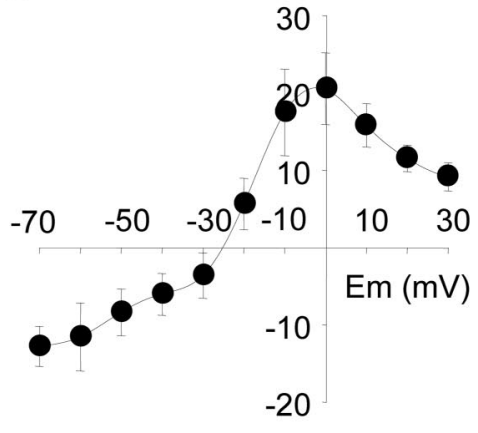

I (pA/pF)
D

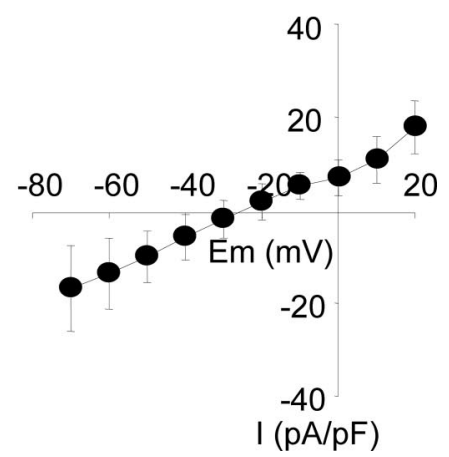

Figure 4. Inflammatory mediator-induced increases in $\mathrm{Cl}^{-}$currents are dependent on intracellular $\mathrm{Ca}^{2+} . \boldsymbol{A}$, IM-induced $\mathrm{Cl}^{-}$currents were recorded while substituting intracellular EGTA (11 $\mathrm{mm})$ with the more rapid $\mathrm{Ca}^{2+}$ chelator, BAPTA $(10 \mathrm{~mm})$. The IM-induced increase in $\mathrm{Cl}^{-}$current was significantly attenuated by $10 \mathrm{~mm} \mathrm{BAPTA}(n=7)$. Additionally, when $\mathrm{Ca}^{2+}$ was buffered to $622 \mathrm{~nm}$ with $1.2 \mathrm{~mm}$ EGTA in the presence of $\mathrm{Cd}^{2+}$ to blockinflux through $\mathrm{Ca}^{2+}$ channels, IMs still produced an increase in inward current at $-60 \mathrm{mV}(n=6) . B$, To further elucidate the mechanisms of $\mathrm{Ca}^{2+}$-dependent activation, the $\mathrm{IM}$-induced $\mathrm{Cl}^{-}$current was measured in the presence of ionic solutions in which $\mathrm{Cs}^{+}$was used to replace intracellular $\mathrm{K}^{+}$and choline was used to replace extracellular $\mathrm{Na}^{+}$, leaving $\mathrm{Cl}^{-}$and $\mathrm{Ca}^{2+}$ unchanged. Currents were elicited with a two-pulse protocol, the first to activate $\mathrm{Ca}^{2+}$ currents and the second to measure the voltage dependence of activation of $\mathrm{Cl}^{-}$currents by IMs using digital subtraction. $C$, IM-induced difference currents $(n=8)$ displayed outward rectification and a downward deflection in the $I-V$ curve as the membrane potential was stepped closer to the reversal potential for $\mathrm{Ca}^{2+}$. These currents reversed direction at approximately $-30 \mathrm{mV} \cdot \mathbf{D}_{1} \mathrm{Cl}^{-}$currents were examined again with $\mathrm{Ca}^{2+}$ buffered to $500 \mathrm{~nm}$ with $1.2 \mathrm{~mm}$ EGTA in the presence of $\mathrm{Cd}^{2+}$ to block influx through $\mathrm{Ca}^{2+}$ channels. Under these conditions, IM-induced $\mathrm{Cl}^{-}$currents displayed a linear $I-V$ curve $(n=7)$. Asterisk $\left({ }^{*}\right)$ denotes significant difference between exposures, where $p<0.05$. Error bars indicate SE.

A

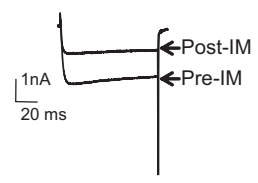

B

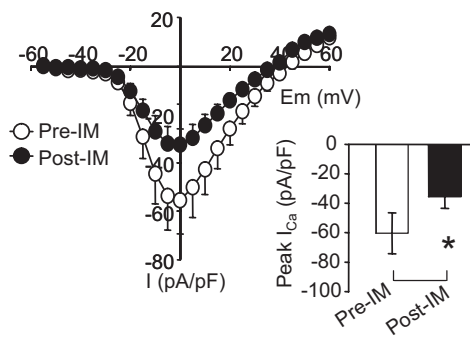

C

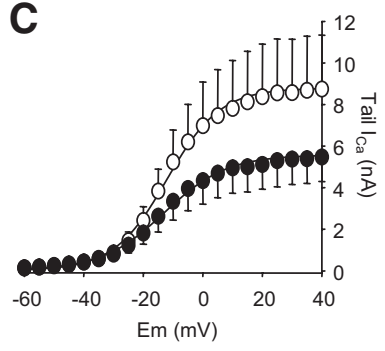

Figure 5. Inflammatory mediators inhibit voltage-gated $\mathrm{Ca}^{2+}$ currents in dural afferents. $\boldsymbol{A}, \mathrm{IM}$-induced changes in isolated $\mathrm{Ca}^{2+}$ currents were recorded before and then after IM application $(n=5) . B$, IM application significantly decreased peak $I_{\mathrm{Ca}}$ density. $C$, Instantaneous $I-V$ curves were plotted from tail currents. IMs produced no change in the voltage dependence of activation. ${ }^{*}$ Significant difference between pre-IM and post-IM, where $p<0.05$. Error bars indicate SE.

induced increase in $\left[\mathrm{Ca}^{2+}\right]_{\text {in }}$ was seen in only 41 of 63 nonlabeled neurons. Interestingly, the magnitude of the evoked increase was significantly larger (Fig. 6D,E) and the decay of the transient (in response to a $30 \mathrm{~s}$ application of IMs) significantly slower (Fig. $6 D, F)$ in dural afferents than in unlabeled afferents. To rule out the possibility that the augmented $\mathrm{Ca}^{2+}$ transients in dural afferents were attributable to DiI labeling, IMs were applied to two additional populations of DiI-labeled afferents: cutaneous afferents retrogradely labeled from the glabrous skin of the hindpaw and muscle afferents retrogradely labeled from the temporalis muscle. Although both populations of afferents can be sensitized by inflammatory mediators (Gold and Traub, 2004; Harriott and Gold, 2009), IM-induced increases in intracellular $\mathrm{Ca}^{2+}$ were only observed in 1 of 10 muscle afferents and in 0 of 12 capsaicinsensitive cutaneous afferents.

To begin to determine whether a combination of inflammatory mediators was actually needed for the sensitization of dural afferents, data were collected from 15 neurons when single mediators were applied sequentially with a 5 min interapplication interval. The order of application was histamine, $\mathrm{PGE}_{2}$, and then bradykinin. As with the combination of mediators, an increase of $20 \%$ above baseline was considered a response. Of these, six neu- rons responded to histamine, nine responded to $\mathrm{PGE}_{2}$, and five responded to bradykinin. Of these, only three neurons "responsive" to histamine responded to at least one other mediator, whereas the same was true for six neurons responsive to $\mathrm{PGE}_{2}$ and all five neurons responsive to bradykinin. Although the fraction of neurons responsive to single mediator was not significantly different from the fraction responsive to the combination, the magnitude of the response was smaller $(p<0.05)$ and the decay faster $(p<0.05)$ than was observed when mediators were applied in combination. The increase in fluorescence above baseline was $0.26 \pm$ $0.03,0.61 \pm 0.18$, and $0.94 \pm 0.09$ for histamine, $\mathrm{PGE}_{2}$, and bradykinin, respectively, whereas $T_{50}$ for decay of the evoked transient was $25.6 \pm 6.1,65.9 \pm 14.2$, and $45.2 \pm 10.5 \mathrm{~s}$ for histamine, $\mathrm{PGE}_{2}$, and bradykinin. These results suggest that the IM-induced increase in $\left[\mathrm{Ca}^{2+}\right]_{\text {in }}$ observed in dural afferents reflects the actions of the combination of mediators rather than the actions of any individual mediator.

\section{The role of $I_{\mathrm{IM}-\mathrm{Cl}}$ in IM-induced sensitization of dural afferents}

In the context of our previous current-clamp data (Harriott and Gold, 2009), the voltage-clamp data presented here suggest that activation of $I_{\mathrm{IM}-\mathrm{Cl}}$ is a depolarizing current that increases the excitability of dural afferents. However, these previous data were recorded using whole-cell patch configuration with $E_{\mathrm{Cl}}(-34$ $\mathrm{mV}$ ) determined by the composition of the bath and electrode solutions. As a result, the "excitatory" effects observed may have been an artifact of our recording conditions. In light of this possibility, it was important to determine whether $E_{\mathrm{Cl}}$ in dural afferents was sufficiently depolarized to account for an IM-induced increase in excitability. $I_{\mathrm{IM}-\mathrm{Cl}}$ was recorded in response to a ramp protocol from +50 to $-100 \mathrm{mV}$ using gramicidin perforated patch to prevent dialysis of intracellular $\mathrm{Cl}^{-}$(Akaike, 1996). To 
isolate the current, extracellular TEA (30 $\mathrm{mM}$ ) was used to block $\mathrm{K}^{+}$currents and choline was used to substitute the remaining $(100 \mathrm{~mm})$ extracellular $\mathrm{Na}^{+}$. Under these recording conditions, $I_{\mathrm{IM}-\mathrm{Cl}}$ was similar to those recorded under traditional whole-cell patch configuration in Figure $4 C$ (Fig. 7$)(n=6)$. More importantly, results from these experiments indicated that the $I_{\mathrm{IM}-\mathrm{Cl}}$ reversal potential in dural afferents is $-27.73 \pm 2.6 \mathrm{mV}$ (Fig. $7 \mathrm{~B}$, inset), which is close to the action potential threshold previously recorded in dural afferents (Harriott and Gold, 2009). These observations suggest that activation of $I_{\mathrm{IM}-\mathrm{Cl}}$ is excitatory in dural afferents.

However, $E_{\mathrm{Cl}}$ is generally depolarized relative to the resting membrane potential in sensory neurons, resulting in the phenomenon of primary afferent depolarization first described almost 50 years ago (Eccles et al., 1962). Despite this fact, activation of $\mathrm{Cl}^{-}$channels via $\mathrm{GABA}_{\mathrm{A}}$ receptors, is generally thought to be inhibitory as a result of membrane shunting and depolarization-induced inactivation of voltage-gated $\mathrm{Na}^{+}$channels (Price et al., 2009). Therefore, we assessed the impact of IMs on the excitability of dural afferents with gramicidin patch recording (Fig. $8 A$ ). Three sets of experiments were performed. In the first, the relative impact of IM-induced activation of $I_{\mathrm{IM}-\mathrm{Cl}}$ on the sensitization of dural afferents $(n=7)$ was assessed with the application of NFA (100 $\mu \mathrm{M})$. Blocking $\mathrm{Cl}^{-}$channels with NFA alone reduced baseline excitability as indicated by an increase in rheobase (Fig. $8 \mathrm{~B}$ ) and a decrease in the slope of the stimulus response function (SRF) (Fig. 8D), although NFA did not impact the AP threshold (Fig. 8C). These changes were associated with an NFA-induced hyperpolarization of the resting membrane potential. The effects of NFA on rheobase and the SRF (i.e., response to suprathreshold stimulation) returned to baseline after a $2 \mathrm{~min}$ washout (Fig. $8 B, D, E$ ). Consistent with previous data (Harriott and Gold, 2009), application of IMs produced a significant reduction in rheobase (Fig. $8 B)$, hyperpolarization of AP threshold (Fig. $8 C$ ), and increase in the slope of the SRF (Fig. 8D). When NFA was applied in the presence of IMs, NFA reversed the IM-induced decrease in rheobase and the IM-induced increase in the SRF slope (Fig. $8 B, D$ ). NFA also reversed the IM-induced membrane depolarization (Fig. $8 E$ ). Interestingly, however, NFA did not reverse the hyperpolarization of AP threshold (Fig. 8C), suggesting that, although activation of $I_{\mathrm{IM}-\mathrm{Cl}}$ is responsible for the most dramatic changes in excitability, it is not responsible for all IM-induced changes.
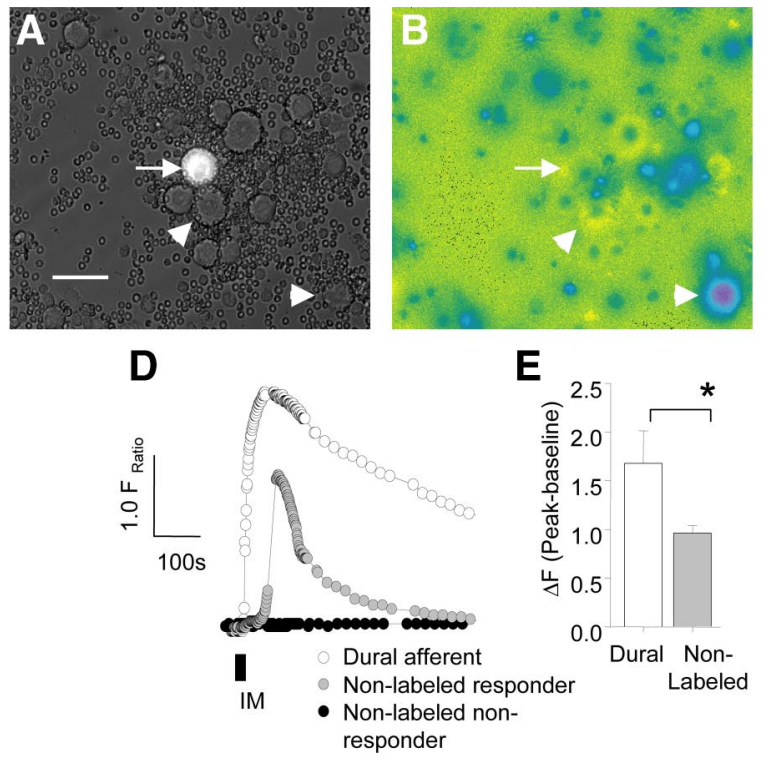

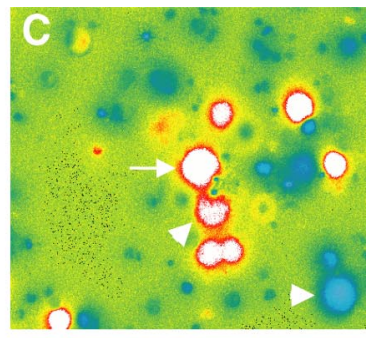

$\mathbf{F}$

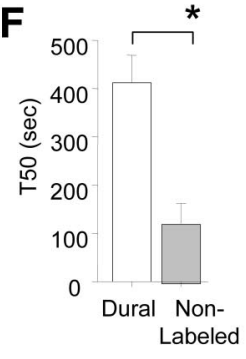

Figure 6. Inflammatory mediator-induced increases in intracellular $\mathrm{Ca}^{2+} . \boldsymbol{A}$, Dural afferents (arrow) and nonlabeled afferents (arrowhead) were identified with epifluorescence illumination. $\boldsymbol{B}, \boldsymbol{C}$, Fura-2 fluorescence ratio was low before IM application in both afferent populations $(\boldsymbol{B})$ and dramatically increases in dural afferents and a subpopulation of nonlabeled neurons after IM application ( $\boldsymbol{C}$. The IM-induced change in the fluorescence ratio was determined by subtracting the baseline ratio from the peak value. The decay of the IM-induced $\mathrm{Ca}^{2+}$ transient was analyzed as time to $50 \%$ decay of the peak $\left(T_{50}\right)$. D, Dural afferents displayed a larger increase in intracellular $\mathrm{Ca}^{2+}$ with a slower decay compared with nonlabeled afferents that responded to IMs. $\boldsymbol{E}, \boldsymbol{F}$, Of the dural (9) and nonlabeled afferents (41) that responded, the increase in fluorescence was significantly greater in dural afferents than nonlabeled afferents $(\boldsymbol{E})$, and the $T_{50}$ was significantly larger in dural afferents than nonlabeled afferents $(\boldsymbol{F})$. *Significant difference between groups, where $p<0.05$. Scale bar: (in $\boldsymbol{A}) \boldsymbol{A}-\boldsymbol{C}, 50 \mu \mathrm{m}$. Error bars indicate SE.
A

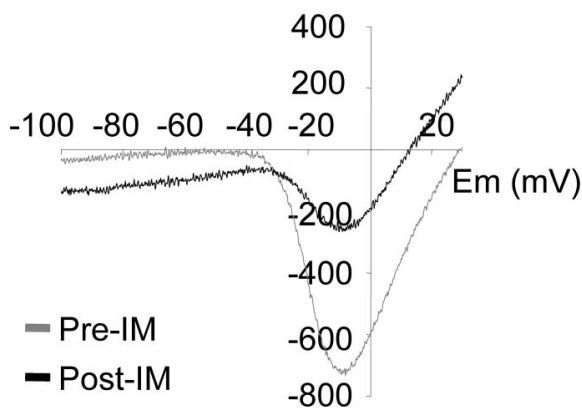

$\mathrm{I}(\mathrm{pA})$
B

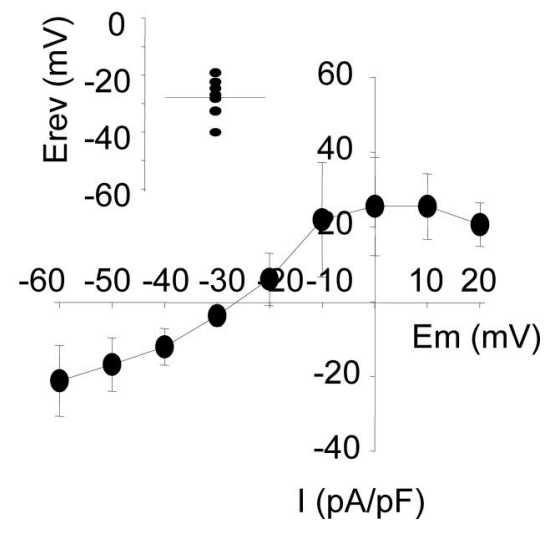

Figure 7. The $\mathrm{Cl}^{-}$equilibrium potential $\left(E_{\mathrm{Cl}}\right)$ is depolarized in dural afferents. To determine the reversal potential for $I_{\mathrm{IM}-\mathrm{Cl}}$ currents were recorded in response to a ramp voltage protocol from +50 to $-100 \mathrm{mV}$ using gramicidin perforated patch to prevent dialysis of intracellular $\mathrm{Cl}^{-}$before and after IM application $(n=6)$. To isolate the current, extracellular TEA was used to block $\mathrm{K}^{+}$currents and choline was used to substitute extracellular $\mathrm{Na}^{+}$. $\boldsymbol{A}$, Traces demonstrate currents recorded under these conditions before (black trace) and then after (gray trace) IM application. $B, I_{I M-C I}$ obtained with digital subtraction was similar to those recorded in Figure $4 C$. Additionally, $I_{\mathrm{IM}-\mathrm{Cl}}$ reversed at $-27.73 \pm 2.6 \mathrm{mV}$ (inset), which was close to the action potential threshold previously recorded in dural afferents. Error bars indicate $S E$.

In the second set of experiments, we tested the prediction that, if membrane depolarization associated with a depolarized $E_{\mathrm{Cl}}$ underlies IM-induced dural afferent sensitization, hyperpolarization of $E_{\mathrm{Cl}}$ should block the sensitizing effects of IMs on dural afferents. To test this prediction, $E_{\mathrm{Cl}}$ was artificially hyperpolarized by decreasing the concentration of $\mathrm{Cl}^{-}$in the electrode solution to $10 \mathrm{~mm}$. Under these recording conditions, the predicted $E_{\mathrm{Cl}}$ is $-68 \mathrm{mV}(n=15)$. In stark contrast to the 19 of 19 dural afferents sensitized by IMs (Harriott and Gold, 2009) with an $E_{\mathrm{Cl}}$ 

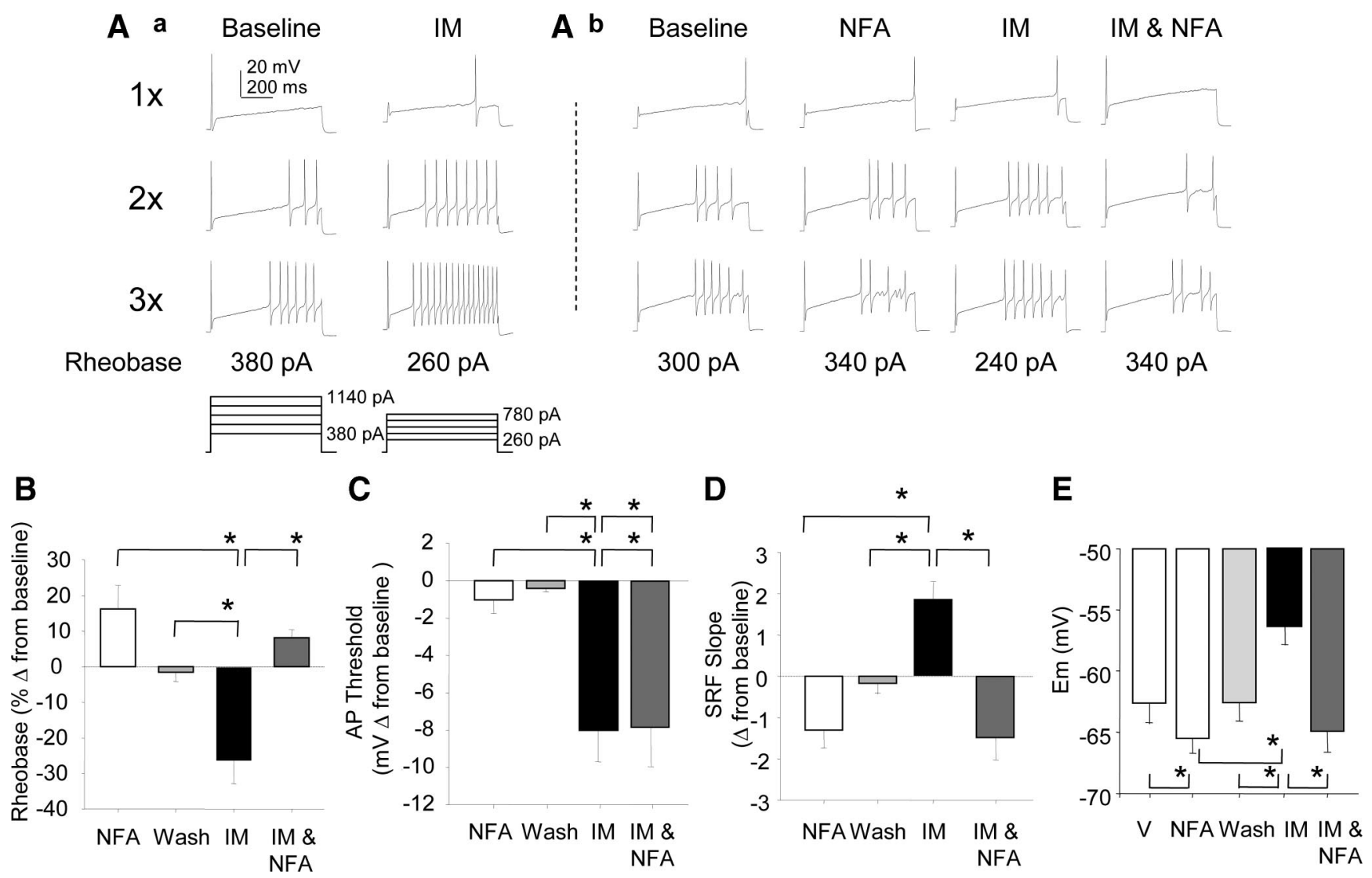

Figure 8. IM-induced sensitization of dural afferents is blocked by niflumic acid. The impact of I IM-c activation was determined with changes in excitability measured in current clamp in the absence and presence of $100 \mu \mathrm{m}$ NFA using gramicidin perforated patch to maintain a physiologically relevant $E_{\mathrm{Cl}}$. $\boldsymbol{A} \boldsymbol{a}$, In the absence of NFA, application of IMs resulted in the sensitization of dural afferents typified by a decrease in rheobase and a leftward shift in the stimulus response function. A typical example of this sensitization is show in $A \boldsymbol{a}$, where the protocol used to stimulate the neuron with depolarizing current injection before (baseline) and after application of IMs is shown beneath the voltage traces. Traces evoked at 1,2, and $3 \times$ rheobase are shown, with 1.5 and $2.5 \times$ rheobase omitted for clarity. To enable detection of a leftward shift in the stimulus response function, rheobase was determined both before and after application of IMs so as to appropriately scale the suprathreshold current injection. $\boldsymbol{A} \boldsymbol{b}$, Voltage traces were evoked in a second neuron before (baseline) and again after the application of NFA (100 $\mu \mathrm{m}$ ), IMs alone, and then the combination of IMs with NFA. Traces evoked after the first wash of NFA have been omitted for clarity. Rheobase determined for each stimulation series is indicated below the voltage traces at 1,2, and $3 \times$ rheobase. The resting membrane potential for the neuron in $\boldsymbol{A} \boldsymbol{a}$ was $-67 \mathrm{mV}$, whereas that in $\boldsymbol{A} \boldsymbol{b}$ was $-64 \mathrm{mV}$. Pooled data from seven neurons studied as in $\boldsymbol{A} \boldsymbol{b}$ are plotted in $\boldsymbol{B}-\boldsymbol{E}$. $\boldsymbol{B}, \mathrm{B}$. $\mathrm{ck}$ ing $\mathrm{Cl}^{-}{ }^{-}$channels with NFA alone reduced baseline excitability as indicated by an increase in rheobase. This effect returned to baseline levels with a 2 min wash. IMs produced a significant decrease in rheobase compared with wash, which was reversed with subsequent NFA application. C, In contrast to the inhibitory NFA effects on rheobase, NFA did not have baseline effects on AP threshold nor was it able to reverse the IM-induced hyperpolarization of AP threshold. D, NFA significantly decreased the slope of the SRF, which returned to baseline levels after wash. IMs produced an increase in slope, which was reversed with NFA application. $\boldsymbol{E}$, Consistent with inhibition of a depolarizing current active at rest, NFA alone hyperpolarized the resting membrane potential and reversed the IM-induced depolarization. *Significant difference between exposures, where $p<0.05$. Error bars indicate SE.

of $-34 \mathrm{mV}$ and the 7 of 7 neurons sensitized by IMs with gramicidin patch recording, an $E_{\mathrm{Cl}}$ of $-68 \mathrm{mV}$ produced an IM-induced decrease in excitability in 5 of 15 dural afferents, as indicated by an increase in rheobase, and produced no detectable change in excitability in an additional 6 of the 15 dural afferents tested. Moreover, an increase in excitability as indicated by a decrease in rheobase was detected in only 4 of 15 dural afferents tested (Fig. 9A). The net effect of IMs in the presence of low intracellular $\mathrm{Cl}^{-}$was a $15.35 \pm 26.9 \%$ increase in rheobase (Fig. $9 B$ ) and no changes in the response to suprathreshold stimuli (Fig. 9D). Nevertheless, as with NFA, the IM-induced hyperpolarization of AP threshold was still present in 14 of 15 neurons tested with a hyperpolarized $E_{\mathrm{Cl}}$ (Fig. 9C).

In the third set of experiments, we sought to confirm the link between the IM-induced $\mathrm{Ca}^{2+}$ transient and the activation of an excitatory $\mathrm{Cl}^{-}$current. IM-induced sensitization of dural afferents was assessed with an electrode solution in which we again substituted $11 \mathrm{~mm}$ EGTA with $10 \mathrm{~mm}$ BAPTA $(n=8)$. In the presence of $10 \mathrm{~mm}$ BAPTA in the electrode solution, a significant decrease in rheobase was only detected in four of eight neurons tested. Furthermore, this decrease in rheobase was significantly less than the percentage decrease in rheobase observed in the presence of $11 \mathrm{~mm}$ EGTA (Fig. 10A,B). The IM-induced increase in the slope of the SRF was also significantly attenuated in the presence of BAPTA (Fig. 10D). In contrast to the results obtained with NFA and the hyperpolarizing shift in $E_{\mathrm{Cl}}, 10 \mathrm{~mm}$ BAPTA also prevented the IM-induced hyperpolarization of AP threshold (Fig. 10 C). These results are consistent with the suggestion that a rapid increase in intracellular $\mathrm{Ca}^{2+}$ is necessary for the activation of $I_{\mathrm{IM}-\mathrm{Cl}}$ and subsequent sensitization of dural afferents and suggest that the $\mathrm{Ca}^{2+}$ transient also contributes to the modulation of voltage-gated $\mathrm{Na}^{+}$currents critical for the establishment of AP threshold.

\section{Discussion}

The purpose of this study was to identify ionic mechanisms underlying IM-induced sensitization of dural afferents. Although at least one experimental outcome, modulation of TTX-R $I_{\mathrm{Na}}$, was expected, our results contain several novel and potentially important observations: (1) the IM-induced block of a $\mathrm{Ca}^{2+}$-dependent $\mathrm{K}^{+}$ 
current, (2) the IM-induced inhibition of voltage-gated $\mathrm{Ca}^{2+}$ currents, (3) the IMinduced activation of $I_{\mathrm{IM}-\mathrm{Cl}}$, and (4) the critical role $I_{\mathrm{IM}-\mathrm{Cl}}$ plays in the sensitization of dural afferents.

The IM-induced increase TTX-R $I_{\mathrm{Na}}$ in dural afferents observed in the present study is consistent with a growing body of literature indicating that $\mathrm{Na}_{\mathrm{V}} 1.8$, the channel underlying the slowly inactivating TTX-R current in nociceptive afferents, is not only a common target for a wide variety of inflammatory mediators but also the dominant channel in nociceptive afferents innervating structures throughout the body (Gold and Caterina, 2008). Results from in vivo studies of dural afferents suggest this channel is also present in the peripheral terminals of nociceptive dural afferents (Strassman and Raymond, 1999) where it is positioned to be regulated by inflammatory mediators released in this structure. The absence of detectable IM-induced changes in TTX-S $I_{\mathrm{Na}}$ suggests that the IM-induced increase in TTX-R $I_{\mathrm{Na}}$ is responsible for increases in AP overshoot and rate of rise (Harriott and Gold, 2009). This increase in $\mathrm{Na}^{+}$ current is also the most likely mechanism underlying the IM-induced decrease in AP threshold. A unique role for TTX-R $I_{\mathrm{Na}}$ in the regulation of AP threshold would account for the observation that the IM-induced hyperpolarization of AP threshold was still observed in the presence of NFA and a hyperpolarized $E_{\mathrm{Cl}}$. Although there is evidence that $\mathrm{PGE}_{2}$ induced modulation of TTX-R $I_{\mathrm{Na}}$ involves the activation of protein kinase $\mathrm{A}$ (PKA) (England et al., 1996; Gold et al., 1998), there is also evidence that PKA activation may be upstream of protein kinase $\mathrm{C}$ (PKC) in dissociated neurons as we were able to block PKA-mediated modulation of TTX-R $I_{\mathrm{Na}}$ with PKC inhibitors (Gold et al., 1998). The results of the present study are consistent with these previous results if the inhibitor effect of BAPTA reflects the inhibition of IM-induced PKC activation. That is, the inhibition of IM-induced activation of PKC by BAPTA would account for the observation that BAPTA attenuated the IM-induced decrease in AP threshold. However, we suggest that it is the biophysical properties of this channel in combination with the fact that it carries the vast majority of $\mathrm{Na}^{+}$current underlying spike initiation in dural afferents that enables activation of $I_{\mathrm{IM}-\mathrm{Cl}}$ to have such a profound influence on afferent excitability.

IM-induced suppression of two $\mathrm{K}^{+}$currents has been described in sensory neurons. One was a $\mathrm{Ca}^{2+}$-dependent $\mathrm{K}^{+}$current underlying a slow afterhyperpolarization in vagal afferents that is blocked by bradykinin and PGE 2 (Cordoba-Rodriguez et al., 1999) that was subsequently described in a small subpopulation of dorsal root ganglion (DRG) neurons (Gold et al., 1996b). These $\mathrm{K}^{+}$currents do not appear to be present in dural afferents. The second, a $\mathrm{K}^{+}$current suppressed by inflammatory mediators including $\mathrm{PGE}_{2}$, is a $\alpha$-dendrotoxin-sensitive current, likely mediated by a $\mathrm{K}^{+}$channel with Kv1.1 properties (Chi and Nicol, 2007). This current has a
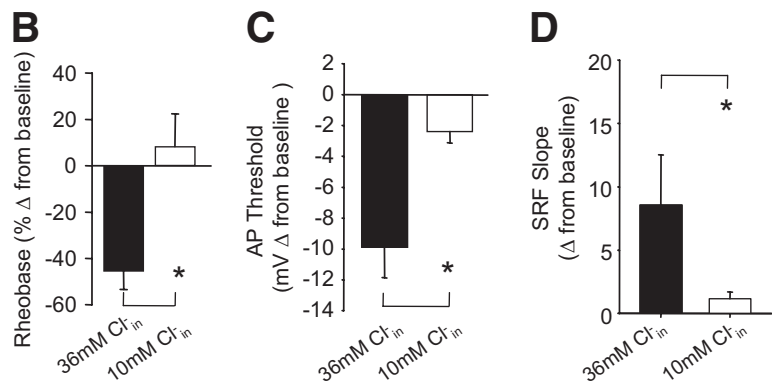

Figure 9. IM-induced sensitization of dural afferent is blocked with a hyperpolarizing shift in $E_{\mathrm{Cl}}$. IM-induced changes in dural afferent excitability was measured in the presence of $10 \mathrm{~mm}$ intracellular $\mathrm{Cl}^{-}$to hyperpolarize the reversal potential for $\mathrm{Cl}^{-}$from produced no effect in 6 of 15 dural afferents, and decreased rheobase in only 4 of 15 dural afferents. $\boldsymbol{B}$, The net effect of IMs in the 列

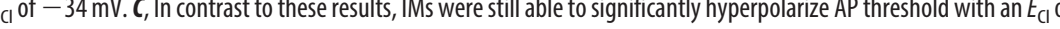
$-68 \mathrm{mV}$. D, However, with an $E_{\mathrm{Cl}}$ of $-68 \mathrm{mV}$, IMs did not shift the response to suprathreshold stimulation. Asterisk $\left(^{*}\right)$ denotes

A

Figure 10. IM-induced sensitization of dural afferent is blocked by BAPTA. Increases in excitability were examined after substituting $11 \mathrm{~mm}$ EGTA for $10 \mathrm{~mm}$ BAPTA $(n=8)$ to determine whether, similar to $I_{\mathrm{IM}-\mathrm{c},}$, IM-induced sensitization was sensitive to apid $\mathrm{Ca}^{2+}$ chelation. $\boldsymbol{A}$, In the presence of $10 \mathrm{~mm}$ BAPTA, four of eight cells exhibited a reduction in rheobase. $\boldsymbol{B}$, On average, there

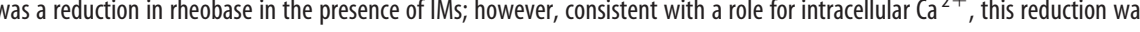

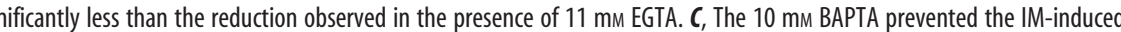
hyperpolarization of AP threshold. D, Additionally, although there was a left shift in the SRF, there was no change in the slope. *Significant difference between pre-IM and post-IM, where $p<0.05$. Error bars indicate SE.

relatively low threshold for activation and contributes to a decrease in current threshold, action potential threshold, and the increase in burst duration in capsaicin-sensitive small-diameter DRG neurons. Despite the inclusion of $\mathrm{PGE}_{2}$ in the IMs used in the present study, no such current was suppressed in dural afferents. Instead, IMs suppressed an iberiotoxin-insensitive $\mathrm{Ca}^{2+}$-dependent $\mathrm{K}^{+}$current. Given the biophysical properties of the IM-sensitive $\mathrm{K}^{+}$current in dural afferents, it is unlikely to contribute to the changes in excitability measured here but may contribute more readily after prolonged stimuli in which it may begin to play a more dominant role as other $\mathrm{K}^{+}$currents begin to inactivate.

The efficacy of BAPTA to block both the activation of $I_{\text {IM-Cl }}$ and the IM-induced sensitization of dural afferents suggests that activation of $I_{\mathrm{IM}-\mathrm{Cl}}$ is dependent on a transient increase in $\left[\mathrm{Ca}^{2+}\right]_{\text {in. }}$. Whether it is the rapid IM-induced increase in $\left[\mathrm{Ca}^{2+}\right]_{\text {in }}$ that is essential for the activation of $I_{\mathrm{IM}-\mathrm{Cl}}$, or that activation of this current requires the rise in $\mathrm{Ca}^{2+}$ coincident to additional second messenger pathway(s) activated by IMs, remains to be determined. Nevertheless, what is clear is that an increase in $\left[\mathrm{Ca}^{2+}\right]_{\text {in }}$ alone, is insufficient for the activation of $I_{\text {IM-Cl}}$. BAPTA will only influence the kinetics of the $\mathrm{Ca}^{2+}$ transient without significantly attenuating the magnitude or duration of the IM-induced increase in $\left[\mathrm{Ca}^{2+}\right]_{\text {in }}$. Furthermore, neither the 
increase in $\left[\mathrm{Ca}^{2+}\right]_{\text {in }}$ alone via the activation of voltage-gated $\mathrm{Ca}^{2+}$ currents or artificially buffering $\left[\mathrm{Ca}^{2+}\right]_{\text {in }}$ to $>600 \mathrm{nM}$ was sufficient to activate a $\mathrm{Cl}^{-}$current in dural afferents. Our data also suggest that, once activated, $I_{\mathrm{IM}-\mathrm{Cl}}$ is not influenced by additional increases in $\left[\mathrm{Ca}^{2+}\right]_{\text {in. }}$. That is, given IM-induced suppression of voltage-gated $\mathrm{Ca}^{2+}$ currents, a decrease in an inward current (i.e., $\mathrm{Ca}^{2+}$ ) at potentials greater than $-30 \mathrm{mV}$ (see below) is likely to account for odd shape of the $I_{\text {IM-Cl }} I-V$ curve (i.e., Fig. 4C), rather than an influence of $\mathrm{Ca}^{2+}$ that is selective for $\mathrm{Cl}^{-}$ influx.

Recent data suggest that after nerve injury, expression of the $\mathrm{Ca}^{2+}$-dependent $\mathrm{Cl}^{-}$channel, bestrophin-1, is upregulated in DRG neurons (Boudes et al., 2009), which may be responsible for the nerve injury-induced increase in $\mathrm{Ca}^{2+}$-dependent $\mathrm{Cl}^{-}$current in DRG (André et al., 2003; Boudes et al., 2009) and nodose ganglion (Lancaster et al., 2002) neurons. Such a channel may also account for the $\mathrm{Cl}^{-}$current activated by bradykinin in vagal afferents (Oh and Weinreich, 2004; Lee et al., 2005). However, this is the first description of $\mathrm{C} \mathrm{Cl}^{-}$current contributing to the IM-induced sensitization of somatic afferents. Furthermore, the IM-activated $\mathrm{Cl}^{-}$current in dural afferents appears to be distinct from $\mathrm{Cl}^{-}$channels upregulated after nerve injury, and bestrophin-1, given that these channels are readily activated by any increase in $\left[\mathrm{Ca}^{2+}\right]_{\mathrm{in}}$, such as that associated with action potential generation (Boudes et al., 2009), whereas $I_{\mathrm{IM}-\mathrm{Cl}}$, once activated, appears to be mostly $\mathrm{Ca}^{2+}$ independent.

Suppression of voltage-gated $\mathrm{Ca}^{2+}$ currents in sensory neurons is generally believed to be one of the primary mechanisms underlying the actions of several spinally administered analgesics (Gold and Caterina, 2008). Nevertheless, $\mathrm{PGE}_{2}$-induced suppression of $\mathrm{Ca}^{2+}$ currents in mouse trigeminal ganglion neurons has been described previously (Borgland et al., 2002). It is therefore possible that the IM-induced suppression of $\mathrm{Ca}^{2+}$ current in dural afferents reflects a similar mechanism of action. However, in contrast to the results obtained with $\mathrm{PGE}_{2}$ in mouse trigeminal ganglion neurons, suppression of $\mathrm{Ca}^{2+}$ currents in dural afferents did not appear to reflect a membrane delimited binding of G-protein subunits that would be expected to shift the voltage dependence of channel activation. Alternatively, the large sustained IM-induced increases in $\left[\mathrm{Ca}^{2+}\right]_{\text {in }}$ raise the possibility that inhibition of $\mathrm{Ca}^{2+}$ currents in dural afferents is mediated by a $\mathrm{Ca}^{2+}$-induced inactivation of $\mathrm{Ca}^{2+}$ channels (Catterall, 2000).

IM-induced suppression of $\mathrm{Ca}^{2+}$ currents in dural afferents may serve as a form of a "brake" to the excitatory IM-induced processes, for example by attenuating the peripheral release of transmitters from nociceptive afferents and, consequently, the neurogenic inflammation mediated by vasoactive neuropeptides in dural afferents (McIlvried et al., 2009). However, a decrease in voltage-gated $\mathrm{Ca}^{2+}$ currents may also contribute indirectly to dural afferent sensitization, as the IM-induced decrease in $\mathrm{Ca}^{2+}$ current is likely to be responsible for the IM-induced decrease in high-threshold $\mathrm{Ca}^{2+}$-dependent $\mathrm{K}^{+}$current.

The most dramatic IM-induced changes in dural afferent excitability are the decrease in rheobase and the shift in the stimulus response function. That IM-induced activation of $I_{\mathrm{IM}-\mathrm{Cl}}$ plays a dominant role in both of these changes is suggested by the observation that both changes were reversed by NFA, attenuated by BAPTA, and switched from being excitatory to inhibitory when $E_{\mathrm{Cl}}$ was hyperpolarized. These observations suggest that the mix of ion channels underlying the excitability of dural afferents is unique from those regulating the excitability of other populations of afferents in which the membrane depolarization associated with the activation of $\mathrm{Cl}^{-}$channels is inhibitory (Price et al., 2009). That $I_{\mathrm{IM}-\mathrm{Cl}}$ does not appear to contribute to the sensitiza- tion of other populations of afferents we have studied (Gold and Traub, 2004; Harriott and Gold, 2009) does not rule out the possibility that the channel contributes to the sensitization of other afferent populations, but it does raise the intriguing possibility that it may be unique to dural afferents.

Although the results of the present study have added several important aspects to our understanding of dural afferents, several caveats must be kept in mind. First, although several lines of evidence suggest that the impact of dural afferent labeling on the properties of dural afferents should be minimal [mast cell degranulation normalized by $10 \mathrm{~d}$ after labeling (Harriott and Gold, 2009); the IM-induced changes in excitability are comparable with those observed in unlabeled sensory neurons (Gold et al., 1996c); and the IM-induced sensitization of other populations of trigeminal ganglion neurons (Harriott and Gold, 2009), even those such as pulpal afferents that require significant tissue destruction to enable retrograde labeling (our unpublished observation), still appears to involve processes distinct from those observed in dural afferents], it is possible that the process of cell labeling has changed the properties of dural afferents. Second, despite evidence from other afferent populations suggesting that mechanisms underlying the actions of inflammatory mediators, as revealed through the study of the afferent cell body in vitro (Gold et al., 1996a), contribute to the sensitization of afferent terminals in vivo (Khasar et al., 1998), the afferent cell body in vitro is only a model of the afferent terminal. With a number of potentially important limitations (i.e., injury, differences in anatomical constraints, etc) associated with this model, additional experiments will be necessary to confirm the contribution of processes identified in the present study to the sensitization of dural afferent terminals in vivo.

Although there is evidence that central mechanisms are involved in triggering migraine, dural afferents appear to be critical for the initiation of migraine pain (Moskowitz et al., 1993; Strassman et al., 1996; Burstein, 2001; Bolay and Moskowitz, 2002). Activating the peripheral terminals of dural afferents produces pain that is identical with a migraine (Ray and Wolff, 1940). Furthermore, there is evidence that neurogenic inflammation of the dura can activate and sensitize this population of afferents during a migraine attack (Strassman et al., 1996; Sarchielli et al., 2000). The data presented here suggest ionic mechanisms that may serve as targets for the development of novel antimigraine therapies. The fact that $\mathrm{Na}_{\mathrm{V}} 1.8$ is present in all dural afferents in which it appears to play the dominant role in spike initiation (Strassman and Raymond, 1999) supports the notion that a selective blocker would not only help other types of pain but may be effective for migraine pain as well. The critical role of $I_{\mathrm{IM}-\mathrm{Cl}}$ in mediating IM-induced sensitization of dural afferents suggest that the ion channel underlying this current and/or the mechanisms underlying the maintenance of the $\mathrm{Cl}^{-}$gradients in dural afferent may be a particularly useful target for the treatment of migraine.

\section{References}

Akaike N (1996) Gramicidin perforated patch recording and intracellular chloride activity in excitable cells. Prog Biophys Mol Biol 65:251-264.

André S, Boukhaddaoui H, Campo B, Al-Jumaily M, Mayeux V, Greuet D, Valmier J, Scamps F (2003) Axotomy-induced expression of calciumactivated chloride current in subpopulations of mouse dorsal root ganglion neurons. J Neurophysiol 90:3764-3773.

Beyak MJ, Ramji N, Krol KM, Kawaja MD, Vanner SJ (2004) Two TTXresistant $\mathrm{Na}^{+}$currents in mouse colonic dorsal root ganglia neurons and their role in colitis-induced hyperexcitability. Am J Physiol Gastrointest Liver Physiol 287:G845-G855.

Bolay H, Moskowitz MA (2002) Mechanisms of pain modulation in chronic syndromes. Neurology 59:S2-S7. 
Borgland SL, Connor M, Ryan RM, Ball HJ, Christie MJ (2002) Prostaglandin $E_{2}$ inhibits calcium current in two sub-populations of acutely isolated mouse trigeminal sensory neurons. J Physiol 539:433-444.

Boudes M, Sar C, Menigoz A, Hilaire C, Péquignot MO, Kozlenkov A, Marmorstein A, Carroll P, Valmier J, Scamps F (2009) Best1 is a gene regulated by nerve injury and required for $\mathrm{Ca}^{2+}$-activated $\mathrm{Cl}^{-}$current expression in axotomized sensory neurons. J Neurosci 29:10063-10071.

Burstein R (2001) Deconstructing migraine headache into peripheral and central sensitization. Pain 89:107-110.

Catterall WA (2000) Structure and regulation of voltage-gated $\mathrm{Ca}^{2+}$ channels. Annu Rev Cell Dev Biol 16:521-555.

Chi XX, Nicol GD (2007) Manipulation of the potassium channel Kv1.1 and its effect on neuronal excitability in rat sensory neurons. J Neurophysiol 98:2683-2692.

Cordoba-Rodriguez R, Moore KA, Kao JP, Weinreich D (1999) Calcium regulation of a slow post-spike hyperpolarization in vagal afferent neurons. Proc Natl Acad Sci U S A 96:7650-7657.

Dolphin AC, Scott RH (1987) Calcium channel currents and their inhibition by $(-)$-baclophen in rat sensory neurons: modulation by guanine nucleotides. J Physiol 386:1-17.

Eccles JC, Magni F, Willis WD (1962) Depolarization of central terminals of group I afferent fibres from muscle. J Physiol 160:62-93.

Edelmayer RM, Vanderah TW, Majuta L, Zhang ET, Fioravanti B, De Felice M, Chichorro JG, Ossipov MH, King T, Lai J, Kori SH, Nelsen AC, Cannon KE, Heinricher MM, Porreca F (2009) Medullary pain facilitating neurons mediate allodynia in headache-related pain. Ann Neurol 65:184-193.

England S, Bevan S, Docherty RJ (1996) PGE2 modulates the tetrodotoxinresistant sodium current in neonaatal rat dorsal root ganglion neurons via the cyclic AMP-protein kinase A cascade. J Physiol 495:429-440.

Gold MS, Caterina MJ (2008) Molecular biology of nociceptor transduction. In: The senses: a comprehensive reference (Basbaum AI, Bushnell MC, eds), pp 43-74. San Diego: Academic.

Gold MS, Traub RJ (2004) Cutaneous and colonic rat DRG neurons differ with respect to both baseline and PGE2-induced changes in passive and active electrophysiological properties. J Neurophysiol 91:2524-2531.

Gold MS, Reichling DB, Shuster MJ, Levine JD (1996a) Hyperalgesic agents increase a tetrodotoxin-resistant $\mathrm{Na}^{+}$current in nociceptors. Proc Natl Acad Sci U S A 93:1108-1112.

Gold MS, Shuster MJ, Levine JD (1996b) Role of a $\mathrm{Ca}^{2+}$-dependent slow afterhyperpolarization in prostaglandin E2-induced sensitization of cultured rat sensory neurons. Neurosci Lett 205:161-164.

Gold MS, Dastmalchi S, Levine JD (1996c) Co-expression of nociceptor properties in dorsal root ganglion neurons from the adult rat in vitro. Neuroscience 71:265-275.

Gold MS, Levine JD, Correa AM (1998) Modulation of TTX-R $I_{\mathrm{Na}}$ by PKC and PKA and their role in $\mathrm{PGE}_{2}$-induced sensitization of rat sensory neurons in vitro. J Neurosci 18:10345-10355.

Hargreaves KM, Swift JQ, Roszkowski MT, Bowles W, Garry MG, Jackson DL (1994) Pharmacology of peripheral neuropeptide and inflammatory mediator release. Oral Surg Oral Med Oral Pathol 78:503-510.

Harriott AM, Gold MS (2008) Serotonin type 1D receptors (5HTR) are differentially distributed in nerve fibres innervating craniofacial tissues. Cephalalgia 28:933-944.

Harriott AM, Gold MS (2009) Electrophysiological properties of dural afferents in the absence and presence of inflammatory mediators. J Neurophysiol 101:3126-3134.

Harriott AM, Dessem D, Gold MS (2006) Inflammation increases the excitability of masseter muscle afferents. Neuroscience 141:433-442.

Jakubowski M, Levy D, Goor-Aryeh I, Collins B, Bajwa Z, Burstein R (2005) Terminating migraine with allodynia and ongoing central sensitization using parenteral administration of COX1/COX2 inhibitors. Headache 45:850-861.

Jakubowski M, Levy D, Kainz V, Zhang XC, Kosaras B, Burstein R (2007) Sensitization of central trigeminovascular neurons: blockade by intravenous naproxen infusion. Neuroscience 148:573-583.

Khasar SG, Gold MS, Levine JD (1998) A tetrodotoxin-resistant sodium current mediates inflammatory pain in the rat. Neurosci Lett 256:17-20.

Lancaster E, Oh EJ, Gover T, Weinreich D (2002) Calcium and calciumactivated currents in vagotomized rat primary vagal afferent neurons. J Physiol 540:543-556.
Lee MG, Macglashan DW Jr, Undem BJ (2005) Role of chloride channels in bradykinin-induced guinea pig airway vagal C-fibre activation. J Physiol 566:205-212.

Lepinski AM, Hargreaves KM, Goodis HE, Bowles WR (2000) Bradykinin levels in dental pulp by microdialysis. J Endod 26:744-747.

Levy D, Burstein R, Kainz V, Jakubowski M, Strassman AM (2007) Mast cell degranulation activates a pain pathway underlying migraine headache. Pain 130:166-176.

Levy D, Zhang XC, Jakubowski M, Burstein R (2008) Sensitization of meningeal nociceptors: inhibition by naproxen. Eur J Neurosci 27:917-922.

Lu SG, Zhang X, Gold MS (2006) Intracellular calcium regulation among subpopulations of rat dorsal root ganglion neurons. J Physiol 577: 169-190.

Maingret F, Coste B, Padilla F, Clerc N, Crest M, Korogod SM, Delmas P (2008) Inflammatory mediators increase Nav1.9 current and excitability in nociceptors through a coincident detection mechanism. J Gen Physiol 131:211-225.

Mcllvried LA, Albers K, Gold MS (2009) Distribution of artemin and GFRalpha3 labeled nerve fibers in the dura mater of rat. Headache 50:442450 .

Moskowitz MA, Nozaki K, Kraig RP (1993) Neocortical spreading depression provokes the expression of c-fos protein-like immunoreactivity within trigeminal nucleus caudalis via trigeminovascular mechanisms. J Neurosci 13:1167-1177.

Nicol GD, Vasko MR, Evans AR (1997) Prostaglandins suppress an outward potassium current in embryonic rat sensory neurons. J Neurophysiol 77:167-176.

Oh EJ, Weinreich D (2004) Bradykinin decreases $\mathrm{K}^{+}$and increases $\mathrm{Cl}^{-}$ conductances in vagal afferent neurones of the guinea pig. J Physiol 558:513-526.

Oshinsky ML (2006) Insights from experimental studies into allodynia and its treatment. Curr Pain Headache Rep 10:225-230.

Pitchford S, Levine JD (1991) Prostaglandins sensitize nociceptors in cell culture. Neurosci Lett 132:105-108.

Price TJ, Cervero F, Gold MS, Hammond DL, Prescott SA (2009) Chloride regulation in the pain pathway. Brain Res Rev 60:149-170.

Ray B, Wolff H (1940) Experimental studies on headache. Pain sensitive structures of the head and their significance in headache. Arch Surg 41:813-856.

Roszkowski MT, Swift JQ, Hargreaves KM (1997) Effect of NSAID administration on tissue levels of immunoreactive prostaglandin E2, leukotriene B4, and (S)-flurbiprofen following extraction of impacted third molars. Pain 73:339-345.

Sarchielli P, Alberti A, Codini M, Floridi A, Gallai V (2000) Nitric oxide metabolites, prostaglandins and trigeminal vasoactive peptides in internal jugular vein blood during spontaneous migraine attacks. Cephalalgia 20:907-918.

Schnizler K, Shutov LP, Van Kanegan MJ, Merrill MA, Nichols B, McKnight GS, Strack S, Hell JW, Usachev YM (2008) Protein kinase A anchoring via AKAP150 is essential for TRPV1 modulation by forskolin and prostaglandin $\mathrm{E}_{2}$ in mouse sensory neurons. J Neurosci 28:4904-4917.

Stewart T, Beyak MJ, Vanner S (2003) Ileitis modulates potassium and sodium currents in guinea pig dorsal root ganglia sensory neurons. J Physiol 552:797-807.

Strassman AM, Raymond SA (1999) Electrophysiological evidence for tetrodotoxin-resistant sodium channels in slowly conducting dural sensory fibers. J Neurophysiol 81:413-424.

Strassman AM, Raymond SA, Burstein R (1996) Sensitization of meningeal sensory neurons and the origin of headaches. Nature 384:560-564.

Vellani V, Mapplebeck S, Moriondo A, Davis JB, McNaughton PA (2001) Protein kinase $\mathrm{C}$ activation potentiates gating of the vanilloid receptor VR1 by capsaicin, protons, heat and anandamide. J Physiol 534:813-825.

Yoshimura N, de Groat WC (1999) Increased excitability of afferent neurons innervating rat urinary bladder after chronic bladder inflammation. J Neurosci 19:4644-4653.

Zhang YH, Vasko MR, Nicol GD (2002) Ceramide, a putative second messenger for nerve growth factor, modulates the TTX-resistant $\mathrm{Na}^{+}$current and delayed rectifier $\mathrm{K}^{+}$current in rat sensory neurons. J Physiol 544: 385-402. 